\title{
Antibody responses to a suite of novel serological markers for malaria surveillance demonstrate strong correlation with clinical and parasitological infection across seasons and transmission settings in The Gambia
}

Lindsey $\mathrm{Wu}^{1 *+}$, Julia Mwesigwa ${ }^{2 \dagger}$, Muna Affara ${ }^{3}$, Mamadou Bah², Simon Correa ${ }^{2}$, Tom Hall ${ }^{4}$, Susheel K. Singh ${ }^{5,6}$, James G. Beeson ${ }^{7,8,9}$, Kevin K. A. Tetteh ${ }^{1}$, Immo Kleinschmidt ${ }^{10,11}$, Umberto D'Alessandro ${ }^{2}$ and Chris Drakeley ${ }^{1}$

\begin{abstract}
Background: As malaria transmission declines, sensitive diagnostics are needed to evaluate interventions and monitor transmission. Serological assays measuring malaria antibody responses offer a cost-effective detection method to supplement existing surveillance tools.

Methods: A prospective cohort study was conducted from 2013 to 2015 in 12 villages across five administrative regions in The Gambia. Serological analysis included samples from the West Coast Region at the start and end of the season (July and December 2013) and from the Upper River Region in July and December 2013 and April and December 2014. Antigen-specific antibody responses to eight Plasmodium falciparum (P. falciparum) antigensEtramp5.Ag1, GEXP18, HSP40.Ag1, Rh2.2030, EBA175 RIII-V, PfMSP1 19, PfAMA1, and PfGLURP.R2 - were quantified using a multiplexed bead-based assay. The association between antibody responses and clinical and parasitological endpoints was estimated at the individual, household, and population level.

(Continued on next page)
\end{abstract}

\footnotetext{
* Correspondence: lindsey.wu@lshtm.ac.uk

${ }^{\dagger}$ Lindsey Wu and Julia Mwesigwa are co-first authors.

'Faculty of Infectious Tropical Diseases, Department of Infection Biology,

London School of Hygiene and Tropical Medicine (LSHTM), London WC1E

7HT, UK

Full list of author information is available at the end of the article
}

(C) The Author(s). 2020 Open Access This article is licensed under a Creative Commons Attribution 4.0 International License, which permits use, sharing, adaptation, distribution and reproduction in any medium or format, as long as you give appropriate credit to the original author(s) and the source, provide a link to the Creative Commons licence, and indicate if changes were made. The images or other third party material in this article are included in the article's Creative Commons licence, unless indicated otherwise in a credit line to the material. If material is not included in the article's Creative Commons licence and your intended use is not permitted by statutory regulation or exceeds the permitted use, you will need to obtain permission directly from the copyright holder. To view a copy of this licence, visit http://creativecommons.org/licenses/by/4.0/ The Creative Commons Public Domain Dedication waiver (http://creativecommons.org/publicdomain/zero/1.0/) applies to the data made available in this article, unless otherwise stated in a credit line to the data. 


\begin{abstract}
(Continued from previous page)
Results: Strong associations were observed between clinical malaria and concurrent sero-positivity to Etramp5.Ag1 (aOR 4.60 95\% Cl 2.98-7.12), PfMSP1 19 (aOR 4.09 95\% Cl 2.60-6.44), PfAMA1 (aOR 2.32 95\% Cl 1.40-3.85), and PFGLURP.R2 (aOR 3.12, 95\% Cl 2.92-4.95), while asymptomatic infection was associated with sero-positivity to all antigens. Village-level sero-prevalence amongst children 2-10 years against Etramp5.Ag1, HSP40.Ag1, and PfMSP1 19 showed the highest correlations with clinical and $P$. falciparum infection incidence rates. For all antigens, there were increased odds of asymptomatic $P$. falciparum infection in subjects residing in a compound with greater than $50 \%$ sero-prevalence, with a 2- to 3-fold increase in odds of infection associated with Etramp5.Ag1, GEXP18, Rh2.2030, $P F M S P 1_{19}$, and PFAMA1. For individuals residing in sero-positive compounds, the odds of clinical malaria were reduced, suggesting a protective effect.

Conclusions: At low transmission, long-lived antibody responses could indicate foci of malaria transmission that have been ongoing for several seasons or years. In settings where sub-patent infections are prevalent and fluctuate below the detection limit of polymerase chain reaction (PCR), the presence of short-lived antibodies may indicate recent infectivity, particularly in the dry season when clinical cases are rare. Serological responses may reflect a persistent reservoir of infection, warranting community-targeted interventions if individuals are not clinically apparent but have the potential to transmit. Therefore, serological surveillance at the individual and household level may be used to target interventions where there are foci of asymptomatically infected individuals, such as by measuring the magnitude of age-stratified antibody levels or identifying areas with clustering of above-average antibody responses across a diverse range of serological markers.
\end{abstract}

Keywords: Malaria, Serology, Surveillance

\section{Background}

As malaria transmission declines, the prevalence of infection becomes increasingly heterogeneous and focal. In low transmission settings, highly sensitive diagnostics are needed to measure subtle changes in malaria incidence, evaluate the effectiveness of community-based interventions, and monitor potential re-introduction after elimination. Evidence suggests that infections below the detection limit of microscopy and rapid diagnostic tests (RDTs) contribute to on-going transmission, but the magnitude of their public health importance is yet to be determined [1-3]. Nucleic acid amplification tests (NAATs), such as ultra-sensitive quantitative polymerase chain reaction (qPCR), can detect less than 1 parasite per microlitre $[4,5]$, but are still sensitive to fluctuations in parasite density during the course of an infection.

Serological assays measuring antibody responses may be a more stable diagnostic alternative, offering a costeffective detection method to supplement existing surveillance tools. A number of studies in The Gambia have observed spatio-temporal variations in antibody responses to malaria over time [6,7], with similar observations in Tanzania [8], Equatorial Guinea [9], and South Africa [10]. The majority of these studies measure longlived antibody responses, which can persist for years in the absence of re-infection. By contrast, new serological markers of recent malaria exposure have been developed based on antigens that elicit shorter-lived antibody responses and may be capable of measuring changes in malaria transmission dynamics over periods as short as $1-2$ years $[11,12]$. These markers require validation with population-representative data from a range of endemic settings, and longitudinal cohort studies provide a unique opportunity for a multi-metric assessment of transmission dynamics using clinical, parasitological, and serological endpoints.

Using a suite of novel serological markers of malaria exposure, this study aimed to determine the correlation of antibody responses with clinical and parasitological endpoints at the individual, household, and population level in rural Gambia over 2 years and estimate the strength of association between serological markers and gold standard metrics of active malaria infection. These findings can support the application of serology in measuring recent malaria transmission and allow selection of markers most suitable for use in future surveillance, particularly for reactive detection strategies in pre- and post-elimination settings.

\section{Methods}

\section{Data and sampling}

To understand the dynamics of malaria infection and the impact of annual mass drug administration (MDA), a prospective cohort study was conducted from 2013 to 2015 in 12 villages across five administrative regionsWest Coast (WCR), North Bank (NBR), Lower River (LRR), Central River (CRR), and Upper River (URR) Regions- as described by Mwesigwa et al. [13]. Plasmodium falciparum (Pf) prevalence measured by polymerase chain reaction (PCR) ranged from 2.27 to $19.60 \%$ in the Central River and Upper River Regions respectively (Fig. 1). Residents above 6 months of age were enrolled 


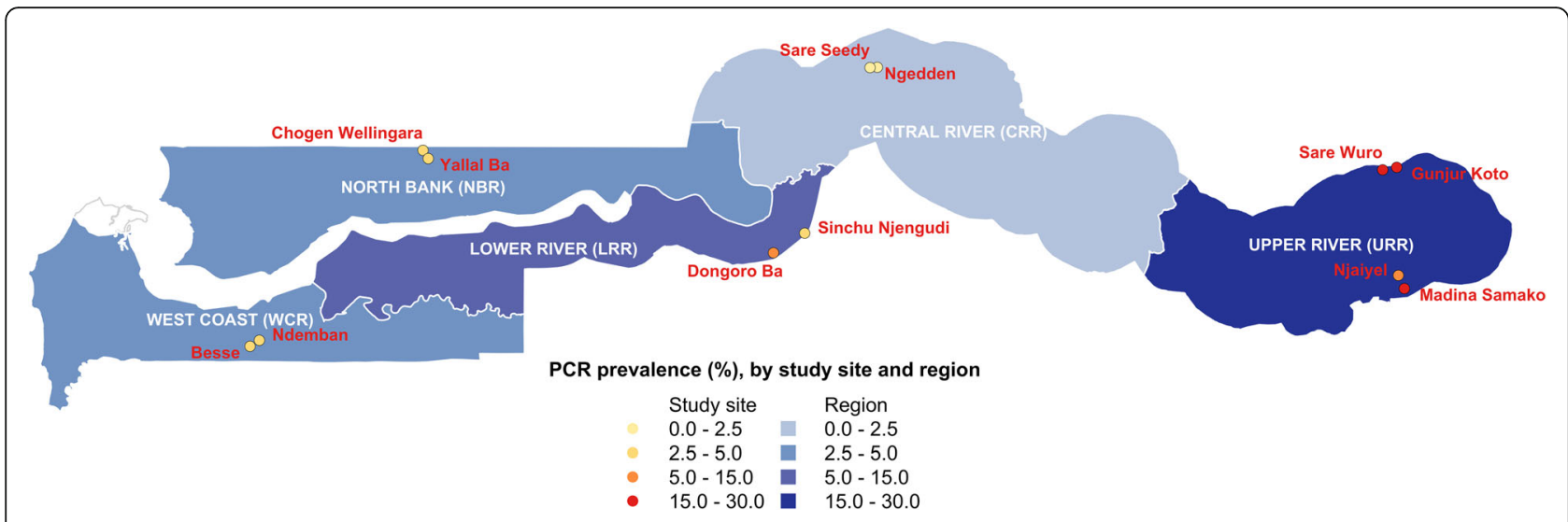

Fig. 1 Map of Malaria Transmission Dynamics Study with regions and study villages by PCR prevalence

in the study, and monthly surveys were conducted during malaria transmission season from June to December each year, during the dry season in April 2014, and prior to the implementation of MDA in May and June 2014 and 2015 (Fig. 2). Individual finger prick blood samples were collected for haemoglobin estimation and on filter paper (Whatman 3 Corporation, Florham Park, NJ, USA) for molecular and serological analysis. Clinical malaria cases included individuals presenting with symptoms at health facilities (e.g. passive case detection) or individuals identified in villages by study nurses with history of fever in the previous $24 \mathrm{~h}$ or axillary temperature $\geq 37.5^{\circ} \mathrm{C}$ and a positive rapid diagnostic test (RDT) result (Paracheck Pf, Orchid Biomedical System, India).

The serological study presented here is a subset of the Malaria Transmission Dynamics Study and included all available samples $(n=4599)$ from a selection of monthly surveys in four villages, totalling 1795 individuals (Fig. 2).
In the West Coast Region (Besse and N'Demban), samples processed for serological analysis were from surveys conducted at the start of the transmission season in July $2013(N=534)$ and at the end of the season in December $2013(N=524)$. In the Upper River Region (URR), serological analysis included all samples collected in Njaiyal and Madina Samako in July $2013(N=778)$, December $2013(N=628)$, April (dry season) $2014(N=$ 799), and December $2014(N=737)$ (Table 1$)$. These regions represent extremes of two transmission intensities, with months selected at the start and end of the transmission season. Samples from clinical PCD cases were linked by study participant identification code to samples from the same individuals collected during routine monthly surveys. To further estimate the association between individual-level antibody responses and concurrent clinical or Pf infection, whole-village monthly survey samples in the West Coast Region and Upper

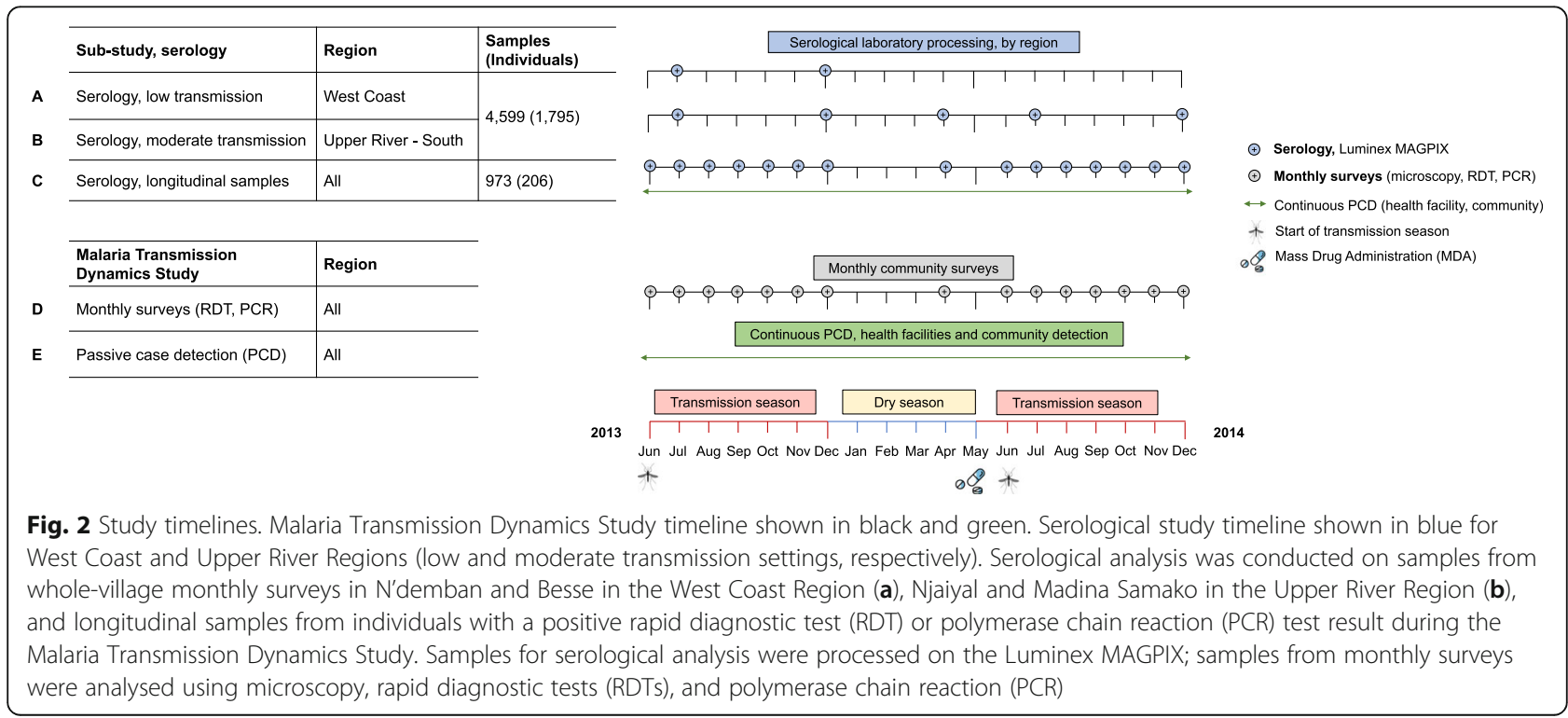


Table 1 Sample size and study subject characteristics by region and survey month. Sample size ( $N$ ) reported as number of individuals in each village for each monthly survey and total number of compounds (with compound defined as a collection of households centrally located around a main residence). Study subject characteristics reported as number and percentage of individuals out of total individuals in each monthly survey. Dashed lines indicate survey months where serological analysis was not conducted in the West Coast Region

\begin{tabular}{|c|c|c|c|c|c|}
\hline & July 2013 & December 2013 & April 2014 & December 2014 & \\
\hline \multicolumn{6}{|c|}{ West Coast Region (WCR) } \\
\hline Sample size $(N)$ & Individuals & & & & Compounds \\
\hline Besse & 400 & 387 & - & - & 69 \\
\hline N'Demban & 134 & 137 & - & - & 24 \\
\hline Subtotal WCR & 534 & 524 & - & - & 93 \\
\hline \multicolumn{6}{|l|}{ Gender, $n(\%)$} \\
\hline Male & $240(46.5)$ & $226(45.0)$ & - & - & \\
\hline Female & $276(53.5)$ & $276(55.0)$ & - & - & \\
\hline \multicolumn{6}{|l|}{ Age category, n (\%) } \\
\hline$<5$ years & $111(21.4)$ & 104 (20.6) & - & - & \\
\hline $5-15$ years & $186(35.9)$ & $194(38.4)$ & - & - & \\
\hline$>15$ years & $221(42.7)$ & $207(41.0)$ & - & - & \\
\hline LLIN use 24 h, n (\%) & $517(96.8)$ & $490(94.2)$ & - & - & \\
\hline \multicolumn{6}{|c|}{ Upper River Region (URR) } \\
\hline Sample size $(N)$ & Individuals & & & & Compounds \\
\hline Njaiyal & 381 & 180 & 290 & 283 & 28 \\
\hline Madina Samako & 397 & 448 & 509 & 454 & 43 \\
\hline Subtotal URR & 778 & 628 & 799 & 737 & 71 \\
\hline \multicolumn{6}{|l|}{ Gender, $n(\%)$} \\
\hline Male & $371(47.9)$ & $285(45.7)$ & $392(49.4)$ & $352(47.9)$ & \\
\hline Female & $403(52.1)$ & 339 (54.3) & $402(50.6)$ & $383(52.1)$ & \\
\hline \multicolumn{6}{|l|}{ Age category, n (\%) } \\
\hline$<5$ years & $164(21.5)$ & $143(23.3)$ & $183(23.3)$ & $169(23.5)$ & \\
\hline $5-15$ years & $260(34.1)$ & $233(37.9)$ & $294(37.5)$ & $252(35.0)$ & \\
\hline$>15$ years & $338(44.4)$ & 239 (38.9) & $308(39.2)$ & 299 (41.5) & \\
\hline LLIN use 24 h, $n(\%)$ & $278(46.6)$ & $244(41.8)$ & $278(46.6)$ & $294(44.0)$ & \\
\hline
\end{tabular}

River Region as described above were combined with an additional subset of 1244 longitudinal samples from 316 individuals who experienced a positive RDT or PCR test result or presented with clinical symptoms at any point during the Malaria Transmission Dynamics Study (Fig. 2). For these individuals, all available samples from the study were processed to longitudinally capture their serological responses before and after a positive RDT or PCR test result.

This study was approved by The Gambia Government/MRC Joint Ethics Committee (SCC1318). Verbal consent was first obtained at village sensitisation meetings, followed by individual written informed consent for all participants. Parents/guardians provided written consent for children less than 17 years, and assent was obtained from children between 12 and 17 years.

\section{Antigen selection and design}

Antigens were selected from an initial screen of 856 candidates on an in vitro transcription and translation (IVTT) protein microarray based on correlation with malaria infection in children [11]. Antigens were generated and expressed in Escherichia coli (E. coli) as glutathione S-transferase (GST)-tagged fusion proteins [20$22]$, with the exception of PfAMA1 expressed in Pichia pastoris as a histidine-tagged protein [15]. Protein purification was conducted by affinity chromatography (Glutathione Sepharose 4B, GE Healthcare Life Sciences) or HisPur Ni-NTA (Invitrogen) for GST- and Histagged proteins, respectively, and concentration, quality, and purity of antigen yield assessed using a Bradford assay and SDS-PAGE. Bacterial lysate from culture of untransformed E. coli was used in assay buffers to 
eliminate background reactivity to $E$. coli proteins that were not specific to malaria target proteins.

Additionally, to account for potential non-malaria reactivity against GST-tagged fusion proteins, GSTcoupled beads were included to quantify GST-specific immunoglobulin (IgG) responses and correct for nonspecific binding. After laboratory processing, there were 71 participant samples with GST antibody responses above 1000 median fluorescence intensity (MFI), which was defined as the threshold to indicate potential nonmalaria-specific binding, and were excluded from further analyses. Tetanus toxoid (TT, Massachusetts Biologic Laboratories) was also included as an internal positive control, assuming that vaccinated Gambians would show antibody responses to this protein target. A summary of antigen constructs and coupling conditions are detailed in Table 2.

\section{Laboratory procedures}

Antigen-specific antibody responses were quantified using the Luminex MAGPIX protocol described in Wu et al. 2019 [23]. Plasma was eluted from $6 \mathrm{~mm}$ dried blood spots (DBS) (4 $\mu \mathrm{l}$ whole blood equivalent) and shaken overnight at room temperature in $200 \mu \mathrm{l}$ of protein elution buffer containing phosphate buffered saline (PBS) ( $\mathrm{pH} 7.2$ ), $0.05 \%$ sodium azide, and $0.05 \%$ Tween20 , yielding an initial 1:50 sample dilution. One day prior to assay processing, samples were diluted to a final 1:500 dilution using $10 \mu \mathrm{l}$ of the 1:50 pre-dilution sample and $90 \mu \mathrm{l}$ of blocking Buffer B to prevent non-specific binding (1xPBS, $0.05 \%$ Tween, $0.5 \%$ bovine serum albumin (BSA), $0.02 \%$ sodium azide, $0.1 \%$ casein, $0.5 \%$ polyvinyl alcohol (PVA), 0.5\% polyvinyl pyrrolidone (PVP), and $1500 \mu \mathrm{g} / \mathrm{ml} \mathrm{E}$. coli extract). Negative and positive controls were also incubated 1 day prior in Buffer B, with negative controls prepared at a 1:500 dilution and Gambian pooled positive controls in a 6-point 5 -fold serial dilution (1:10-1:31,250). The positive control was based on a pool of 22 serum samples from malaria hyperimmune individuals in The Gambia, and ten individual plasma samples from European malaria-naive adults were used as negative controls.

Samples were prepared for diagnostic PCR as described by Mwesigwa et al. [13]. Briefly, DNA was extracted from three 6-mm DBS using the automated QIAxtractor robot (Qiagen). Negative and positive (3D7) controls were included to control for cross contamination and DNA extraction efficiency, respectively. The DBS were lysed by incubation in tissue digest buffer at $60^{\circ} \mathrm{C}$ for $1 \mathrm{~h}$ and digested eluates were applied onto capture plates, washed, and the DNA eluted into $80 \mu \mathrm{l}$. The extracted DNA $(4 \mu \mathrm{l})$ was used in a nested PCR, amplifying the multi-copy Plasmodium ribosomal RNA gene sequences using genus and species specific primers [24].
All PCR products were run using the QIAxcel capillary electrophoresis system (Qiagen), using the screening cartridge and 15-1000 bp-alignment marker. Results were exported and double scored using both the QIAxcel binary scoring function and manually by visualisation of the gel images and discrepancies were scored by a third independent reader. All readers were blinded to participant survey data.

\section{Statistical analyses}

Data analysis was based on total IgG levels to five antigens as potential markers of sero-incidence [11] - early transcribed membrane protein 5 (Etramp5.Ag1), gametocyte export protein 18 (GEXP18), heat shock protein 40 (HSP40.Ag1), erythrocyte-binding antigen 175 RIII-V (EBA175), and reticulocyte binding protein homologue 2 (Rh2.2030). Three antigens associated with long-lived antibody response- $-P$. falciparum merozoite surface antigen $119-\mathrm{kDa}$ carboxyterminal region $\left(P f \mathrm{MSP} 1_{19}\right), P$. falciparum apical membrane antigen 1 (PfAMA1), and P. falciparum glutamate-rich protein, region 2 (PfGLURP.R2)-were included as a comparison, which have historically been used to assess seroconversion rates over time $[8,9]$ and have also previously been studied in The Gambia [6, 7]. For antigens associated with long-lived antibodies (PfMSP1 19, PfAMA1, PfGLURP.R2), individuals residing in an endemic region previously exposed to malaria, but not recently infected, may still have residual antibody levels that are significantly higher than malaria-naïve individuals in non-endemic regions. Therefore, a two-component Gaussian mixture model was used to define distributions of negative and positive antibody levels, expressed in units of median fluorescence intensity (MFI). Sero-positivity thresholds were defined as the mean $\log$ MFI values plus two standards deviations of the negative distribution [25]. Mixture models were estimated using the 'normalmixEM' function in the 'mixtools' package v1.0.4 in $\mathrm{R}$ version 3.6.1. For antigens associated with shorter-lived antibodies where statistical evidence of a bimodal distribution of antibody responses in the population was not strong given the more rapid decay of antibody levels post-infectionEtramp5.Ag1, GEXP18, HSP40.Ag1, EBA175, and Rh2.2030 - the sero-positivity threshold was defined by the mean log MFI plus three standard deviations of 71 malarianaïve European blood donors used as negative controls.

Individual-level association between antibody response and the concurrent odds of clinical malaria (passively detected via the health facility or study nurses in the community) or asymptomatic $P$. falciparum infection (actively detected using PCR from monthly survey samples) were assessed using generalised estimating equations (GEE). Analysis was adjusted for age group ( $1-5$ years, 6-15 years, and greater than 15 years) and use of long-lasting insecticide-treated nets (LLINs) in the last $24 \mathrm{~h}$ and allowed for clustering at the compound level, where 
compound is a collection of households centrally located around a main residence. The magnitude of the association between antibody response and odds of infection was evaluated for interaction with age group. Based on a subset of longitudinal samples, individual-level association between antibody response and recent infection in the previous 4 months (as opposed to current infection at the same time point) was also assessed using a GEE model, adjusted for age group, LLIN use, and random effects at the compound level, as above.

Using a GEE model, individual-level odds of clinical malaria or asymptomatic infection was assessed for association with residing in the same compound as a seropositive individual. Similarly, the association between individual odds of infection and compound-level seroprevalence $(<50 \%$ or $>50 \%)$ was assessed using a mixedeffects generalised linear model adjusted for age group and LLIN use and random effects at the compound level, which also accounts for the potential effect of geographical differences in transmission intensity. To ensure that estimates are not biased by the sero-prevalence of small compounds, analysis was weighted by the number of individuals in the compound (whose sero-status was assessed) and only included compounds with at least four individuals. Models were fit using the 'geeM' and 'Ime4' packages in $\mathrm{R}$ version 3.14 .

Village-level sero-prevalence amongst children aged 210 years in the West Coast Region and Upper River Region in July and December $2013(n=1001)$ was compared against all-age clinical and $P$. falciparum infection incidence rates from the same months, the latter of which were previously reported by Mwesigwa et al. [13]. Monthly clinical and P. falciparum infection incidence rates were defined respectively as the number of new clinical cases or P. falciparum infections (PCR-positive individuals who were PCR-negative in the previous monthly survey) divided by total person years at risk (PYAR). This age range was selected to align with other routine surveillance metrics, such as annual parasite index (API), commonly using this age group as a sentinel population. The strength of the relationship between village-level incidence rates and sero-prevalence for each antigen was assessed using Pearson's correlation coefficient. Data from April and December 2014 were not included in the analysis because clinical incidence and $P f$ infection rates from these surveys have not yet been reported.

\section{Results}

Village-level sero-prevalence

Data from 2001 individuals were available for analysis of antibody responses from 5572 samples between June 2013 and December 2014 (Fig. 2). Based on whole-village monthly survey data in the West Coast and Upper River Regions, slightly more than half of participants were female in both the West Coast Region (55.0\%) and the Upper River Region (54.3\%), and there was higher LLIN use in the West Coast Region (96.8\%) compared to the Upper River Region (46.6\%) (Table 1). In the West Coast Region, $P$. falciparum infection rate in December 2013 (0.67 95\% CI 0.40-1.13) was three times higher than at the start of the transmission season in July $2013(0.23$ 95\% CI 0.13-0.39) (Table 3). In the Upper River Region, $P$. falciparum infection rate in December 2013 (2.87 95\% CI 2.36-3.50) was five times higher than July 2013 (0.56 95\% CI 0.42-0.74) (Table 3). Sero-prevalence amongst $2-10$ years olds in the West Coast Region ranged from $1.0 \%$ (95\% CI $0.0-2.3$ ) for $\mathrm{Rh} 2.2030$ in July 2013 (start of the transmission season) to 13.7\% (95\% CI 8.9-18.5) for Etramp5.Ag1 in December 2013 (end of transmission season) (Table 3). In the Upper River Region, sero-prevalence across all antigens was higher, ranging from $5.1 \%(95 \%$ CI $2.5-7.7)$ for Pf MSP $1_{19}$ in July 2013 to $36.3 \%$ (95\% CI 30.2-42.3) for GEXP18 in December 2013 (Table 3).

In the Upper River Region in 2014, no statistically significant differences in sero-prevalence amongst 2-10 year olds were observed for any antigen (Additional file 1 - Table S1). It should be noted that MDA was implemented in May-June 2014, so results may not be comparable to 2013 prior to intervention. Sero-prevalence in this age group was highly correlated with clinical malaria and $P$. falciparum infection incidence rates (Fig. 3, Table 4).

In both regions in July and December 2013, correlations between $P$. falciparum infection rate and seroprevalence were strongest for Etramp5.Ag1 $(\rho=0.99)$, HSP40.Ag1 $(\rho=0.99), \quad$ PfMSP1 $19 \quad(\rho=0.99), \quad$ and Rh2.2030 $(\rho=0.94)$. Incidence of clinical malaria had the strongest correlations with Etramp5.Ag1 $(\rho=0.97)$, PfMSP1 $19 \quad(\rho=0.95), \quad$ PfGLURP.R $2 \quad(\rho=0.92), \quad$ and HSP40.Ag1 $(\rho=0.90)$. After excluding December 2013 data from the Upper River Region as a potential outlier, correlations with both clinical incidence and P. falciparum infection rates remained high for Etramp5.Ag1 $\left(p=0.92\right.$ and $p=0.95$, respectively) and $\mathrm{PfMSP}_{19}(p=$ 0.90 and $p=0.93$, respectively). These correlations are based on few data points, with only three observations when excluding the Upper River Region in December 2013.

\section{Individual-level association between clinical malaria, asymptomatic $P$. falciparum infection, and concurrent sero-positivity}

The odds of clinical malaria were higher in individuals sero-positive to six (out of eight) of the antigens analysed (Etramp5.Ag1, GEXP18, Rh2.2030, PfMSP1 19 , PfAMA1, and PfGLURP.R2) (Fig. 4a, Table 5). After 
Table 2 Summary of antigens in multiplex Luminex panel

\begin{tabular}{|c|c|c|c|c|c|c|c|}
\hline Gene ID & $\begin{array}{l}\text { Antigen } \\
\text { name }\end{array}$ & Strain & $\begin{array}{l}\text { Antigen bead coupling } \\
\text { concentration }(\mu \mathrm{g} / \mathrm{mL})\end{array}$ & $\begin{array}{l}\text { Purification } \\
\text { tag }\end{array}$ & Location & Description & Reference \\
\hline $\begin{array}{l}\text { PF3D7_ } \\
0930300\end{array}$ & $P f M S P 1_{19}$ & Wellcome & 42.31 & GST & $\begin{array}{l}\text { Merozoite } \\
\text { surface }\end{array}$ & $\begin{array}{l}19 \mathrm{kDa} \text { fragment of MSP1 } \\
\text { molecule }\end{array}$ & [14] \\
\hline $\begin{array}{l}\text { PF3D7_- } \\
1133400\end{array}$ & PfAMA1 & FVO & 3.90 & $\mathrm{His}_{x 6}$ & $\begin{array}{l}\text { Sporozoite/ } \\
\text { merozoite }\end{array}$ & Apical membrane antigen 1 & [15] \\
\hline $\begin{array}{l}\text { PF3D7_- } \\
1035300\end{array}$ & PfGLURP.R2 & F32 & 9.22 & N/A & Merozoite & Glutamate-rich protein R2 & [16] \\
\hline $\begin{array}{l}\text { PF3D7_- } \\
0731500\end{array}$ & $\begin{array}{l}\text { EBA175 RIII- } \\
V\end{array}$ & $3 \mathrm{D} 7$ & 408.32 & GST & Merozoite & $\begin{array}{l}\text { Erythrocyte-binding antigen- } \\
175 \text { Region III-V }\end{array}$ & [17] \\
\hline $\begin{array}{l}\text { PF3D7_- } \\
1335400\end{array}$ & Rh2.2030 & D10 & 244.30 & GST & Merozoite & $\begin{array}{l}\text { Reticulocyte binding protein } \\
\text { homologue } 2\end{array}$ & [18] \\
\hline $\begin{array}{l}\text { PF3D7_ } \\
0532100\end{array}$ & Etramp5.Ag1 & $3 \mathrm{D} 7$ & 34.93 & GST & iRBC/PVM & $\begin{array}{l}\text { Early transcribed membrane } \\
\text { protein } 5\end{array}$ & [19] \\
\hline $\begin{array}{l}\text { PF3D7_ } \\
0402400\end{array}$ & GEXP18 & $3 \mathrm{D} 7$ & 625.00 & GST & Gametocytes & $\begin{array}{l}\text { Gametocyte exported protein } \\
18\end{array}$ & [11] \\
\hline $\begin{array}{l}\text { PF3D7_ } \\
0501100.1\end{array}$ & HSP40.Ag1 & 3D7 & 42.54 & GST & $\begin{array}{l}\text { iRBC/ } \\
\text { gametocytes }\end{array}$ & Heat shock protein 40 , type II & [11] \\
\hline- & GST & - & 85.99 & - & - & GST expression tag & \\
\hline- & $\pi$ & - & 61.52 & - & - & Tetanus toxoid & \\
\hline
\end{tabular}

iRBC infected red blood cell, PVM parasitophorous vacuole membrane, GST glutathione S-transferase

adjusting for age and LLIN use, clinical malaria was associated with concurrent sero-positivity to four antigens (Etramp5.Ag1, PfMSP1 19, PfAMA1, and PfGLURP.R2), while odds of asymptomatic infection were strongly associated with sero-positivity to all antigens. Amongst individuals sero-positive for Etramp5.Ag1, there was increased odds of both clinical malaria (aOR 4.60, 95\% CI $2.98-7.12, p<0.001)$ and asymptomatic infection (aOR 3.33, 95\% CI 2.72-4.08, $p<0.001$ ) (Table 5). Association with clinical malaria was slightly lower in individuals sero-positive for $P f M S P 1_{19}$ (aOR 4.09, 95\% CI 2.60-
6.44, $p<0.001$ ), PfGLURP.R2 (aOR 3.12, 95\% CI 2.12$4.59, p<0.001$ ), and PfAMA1 (aOR 2.32, 95\% CI 1.40$3.85 p=0.001$ ). Odds of asymptomatic infection in individuals sero-positive to GEXP18 (aOR 3.12, 95\% CI 2.50-3.90, $p<0.001$ ), Rh2.2030 (aOR 3.06, 95\% CI 2.403.89, $p<0.001$ ), PfAMA1 (aOR 3.80, 95\% CI 2.95-4.90, $p<0.001$ ), and PfGLURP.R2 (aOR 3.80 95\% CI $2.92-$ $4.95, p<0.001)$ was similar to Etramp5.Ag1. Additionally, a subset of longitudinal samples were used to explore the dynamics of antibody responses following infection. After adjusting for age group and LLIN use,

Table 3 Regional sero-prevalence (ages 2-10 years) by antigen and all-age incidence rates for clinical malaria and Pf infection. Mean sero-prevalence (\%) and incidence rates with 95\% Cl shown in parentheses

\begin{tabular}{|c|c|c|c|c|}
\hline & \multicolumn{2}{|c|}{ West Coast Region (WCR) } & \multicolumn{2}{|c|}{ Upper River Region (URR) } \\
\hline & July 2013 & December 2013 & July 2013 & December 2013 \\
\hline Clinical incidence rate & $0.08(0.04-0.21)$ & $0.14(0.04-0.44)$ & $0.13(0.04-0.39)$ & $0.21(0.1-0.51)$ \\
\hline Pf infection rate & $0.23(0.13-0.39)$ & $0.67(0.40-1.13)$ & $0.56(0.42-0.74)$ & $2.87(2.36-3.50)$ \\
\hline \multicolumn{5}{|c|}{ Sero-prevalence (ages 2-10 years) } \\
\hline & $n=205$ & $n=197$ & $n=275$ & $n=324$ \\
\hline Etramp5.Ag1 & $4.4 \%(1.6-7.2)$ & $13.7 \%(8.9-18.5)$ & $8.7 \%(5.4-12.1)$ & $33.3 \%(27.4-39.3)$ \\
\hline GEXP18 & $11.7 \%(7.3-16.1)$ & $12.7 \%(8.0-17.3)$ & $25.1 \%(20.0-30.2)$ & $36.3 \%(30.2-42.3)$ \\
\hline HSP40.Ag1 & $5.4 \%(2.3-8.5)$ & $6.1 \%(2.8-9.4)$ & $8.4 \%(5.1-11.6)$ & $23.8 \%(18.4-29.1)$ \\
\hline Rh2.2030 & $1.0 \%(0.0-2.3)$ & $1.0 \%(0.0-2.4)$ & $9.8 \%(6.3-13.3)$ & $25.4 \%(19.9-30.9)$ \\
\hline EBA175 & $1.5 \%(0.0-3.1)$ & $1.0 \%(0.0-2.4)$ & $7.3 \%(4.2-10.3)$ & $15.8 \%(11.2-20.5)$ \\
\hline PfMSP $_{19}$ & $2.9 \%(0.6-5.2)$ & $8.1 \%(4.3-11.9)$ & $5.1 \%(2.5-7.7)$ & $22.1 \%(16.8-27.3)$ \\
\hline PfAMA1 & $4.4 \%(1.6-7.2)$ & $4.1 \%(1.3-6.8)$ & $17.8 \%(13.3-22.3)$ & $33.3 \%(27.4-39.3)$ \\
\hline PFGLURP.R2 & $4.4 \%(1.6-7.2)$ & $8.1 \%(4.3-11.9)$ & $16.4 \%(12.0-20.7)$ & $30.4 \%(24.6-36.2)$ \\
\hline
\end{tabular}


Table 4 Pearson's correlation coefficients between regional sero-prevalence (ages 2-10 years) and all-age incidence rates for clinical malaria and Pf infection. Correlation estimates are based on data from the West Coast Region (WCR) and Upper River Region (URR) in July and December 2013. Correlations excluding data from URR December 2013 are shown in brackets

\begin{tabular}{|c|c|c|}
\hline \multirow[t]{2}{*}{ Antigen } & \multicolumn{2}{|c|}{ Pearson's correlation coefficient } \\
\hline & $\begin{array}{l}\text { Sero-prevalence vs. clinical } \\
\text { incidence rate }\end{array}$ & $\begin{array}{l}\text { Sero-prevalence vs. } P \boldsymbol{P} \\
\text { infection incidence rate }\end{array}$ \\
\hline Etramp5.Ag1 & $0.97[0.92]$ & $0.99[0.95]$ \\
\hline GEXP18 & $0.85[0.42]$ & $0.87[0.34]$ \\
\hline HSP40.Ag1 & $0.90[0.56]$ & $0.99[0.48]$ \\
\hline Rh2.2030 & $0.88[0.36]$ & $0.94[0.28]$ \\
\hline EBA175 & $0.85[0.29]$ & $0.91[0.21]$ \\
\hline PfMSP1 $_{19}$ & $0.95[0.90]$ & $0.99[0.93]$ \\
\hline PfAMA1 & $0.85[0.34]$ & $0.89[0.26]$ \\
\hline PfGLURP.R2 & $0.92[0.62]$ & $0.93[0.55]$ \\
\hline
\end{tabular}

antibody responses to six out of eight antigens were significantly associated with infection (clinical, RDTpositive or PCR-positive) in the previous 4 months. Antibody levels against Etramp5.Ag1 were most strongly associated with previous infection (aOR 1.44 95\% CI $1.19-1.75, p<0.001$ ), followed by PfAMA1 (aOR 1.33
95\% CI 1.16-1.53, $p<0.001$ ), EBA175 (aOR 1.26 95\% CI $1.09-1.46, p=0.002$ ), GEXP18 (aOR 1.23 95\% CI $1.03-$ 1.47, $p=0.021$ ), PfMSP1 19 (aOR $1.2195 \%$ CI 1.04-1.41, $p=0.012$ ), and Rh2.2030 (aOR 1.20 95\% CI 1.03-1.39, $p=0.020)$.

\section{Individual-level odds of clinical malaria, asymptomatic infection when residing in compounds with sero-positive individuals}

The odds of clinical malaria were reduced for individuals residing in the same compound with an individual sero-positive to any of the eight antigens (Fig. 4b, Table 6), from an $83 \%$ reduction if residing in the same compound as an individual sero-positive for Etramp5.Ag1 (aOR 0.17, 95\% CI 0.03-0.89, $p=0.036$ ) to a $95 \%$ reduction if residing in the same compound as someone sero-positive for PfAMA1 (aOR 0.05, 95\% CI $0.01-0.52, p=0.011)$. Conversely, the odds of asymptomatic infection were positively associated with residing in the same compound as sero-positive individuals for five antigens (Etramp5.Ag1, GEXP18, Rh2.2030, PfMSP1 1 , and PfAMA1). Adjusted odds of asymptomatic infection was nearly 3 -fold higher if residing with an individual sero-positive for Etramp5.Ag1 (aOR 2.87, 95\% CI 1.62-5.07, $p<0.001)$ and for GEXP18 (aOR 2.61, 95\% CI 1.54-4.42, $p<0.001$ ).

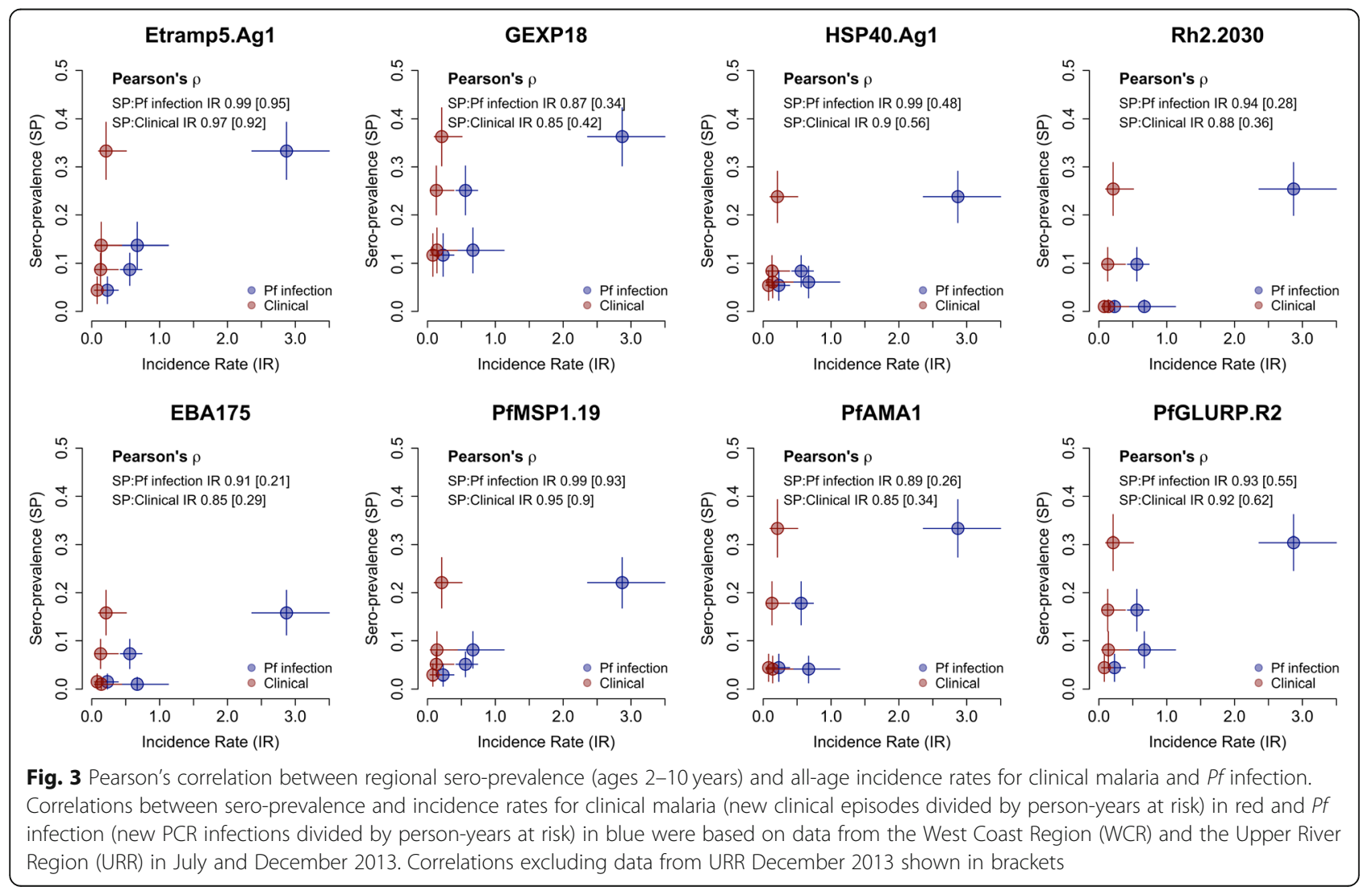


Table 5 Odds of clinical malaria and asymptomatic infection by individual-level serological status, unadjusted and adjusted for age group ( $<5$ years, $5-15$ years, and $>15$ years) and LLIN use in the last $24 \mathrm{~h}$

\begin{tabular}{|c|c|c|c|c|c|c|}
\hline \multicolumn{7}{|c|}{ Odds of clinical malaria or asymptomatic infection amongst sero-positive individuals, by antigen } \\
\hline & \multicolumn{3}{|c|}{ Unadjusted } & \multicolumn{3}{|c|}{ Adjusted } \\
\hline & $\overline{\mathrm{OR}}$ & $95 \% \mathrm{Cl}$ & $\boldsymbol{p}$ value & $\mathrm{aOR}$ & $95 \% \mathrm{Cl}$ & $\boldsymbol{p}$ value \\
\hline \multicolumn{7}{|l|}{ Etramp5.Ag1 } \\
\hline Clinical malaria & 5.88 & $3.44-10.03$ & $<0.001$ & 4.60 & $2.98-7.12$ & $<0.001$ \\
\hline Asymptomatic infection & 3.20 & $2.64-3.88$ & $<0.001$ & 3.33 & $2.72-4.08$ & $<0.001$ \\
\hline \multicolumn{7}{|l|}{ GEXP18 } \\
\hline Clinical malaria & 2.57 & $1.44-4.61$ & 0.002 & 1.48 & $0.90-2.41$ & 0.122 \\
\hline Asymptomatic infection & 2.94 & $2.38-3.64$ & $<0.001$ & 3.12 & $2.50-3.90$ & $<0.001$ \\
\hline \multicolumn{7}{|l|}{ HSP40.Ag1 } \\
\hline Clinical malaria & 1.67 & $0.88-3.18$ & 0.119 & 0.99 & $0.59-1.65$ & 0.956 \\
\hline Asymptomatic infection & 2.53 & $2.06-3.10$ & $<0.001$ & 2.64 & $2.09-3.33$ & $<0.001$ \\
\hline \multicolumn{7}{|l|}{ Rh2.2030 } \\
\hline Clinical malaria & 2.20 & $1.10-4.38$ & 0.025 & 1.28 & $0.77-2.12$ & 0.338 \\
\hline Asymptomatic infection & 2.45 & $1.98-3.03$ & $<0.001$ & 3.06 & $2.40-3.89$ & $<0.001$ \\
\hline \multicolumn{7}{|l|}{ EBA175 } \\
\hline Clinical malaria & 1.37 & $0.67-2.81$ & 0.390 & 1.54 & $0.86-2.75$ & 0.147 \\
\hline Asymptomatic infection & 2.09 & $1.74-2.51$ & $<0.001$ & 2.86 & $2.21-3.72$ & $<0.001$ \\
\hline \multicolumn{7}{|l|}{$P f M S P 1_{19}$} \\
\hline Clinical malaria & 3.83 & $1.95-7.51$ & $<0.001$ & 4.09 & $2.60-6.44$ & $<0.001$ \\
\hline Asymptomatic infection & 2.29 & $1.82-2.88$ & $<0.001$ & 2.49 & $1.90-3.27$ & $<0.001$ \\
\hline \multicolumn{7}{|l|}{ PfAMA1 } \\
\hline Clinical malaria & 2.21 & $1.25-3.90$ & 0.006 & 2.32 & $1.40-3.85$ & 0.001 \\
\hline Asymptomatic infection & 2.62 & $2.12-3.24$ & $<0.001$ & 3.80 & $2.95-4.90$ & $<0.001$ \\
\hline \multicolumn{7}{|l|}{ PfGLURP.R2 } \\
\hline Clinical malaria & 2.17 & $1.28-3.68$ & 0.004 & 3.12 & $2.12-4.59$ & $<0.001$ \\
\hline Asymptomatic infection & 2.38 & $1.96-2.89$ & $<0.001$ & 3.80 & $2.92-4.95$ & $<0.001$ \\
\hline
\end{tabular}

If residing in a compound with individuals seropositive to Rh2.2030, PfMSP1 19 , or PfAMA1, the odds of asymptomatic infection were all nearly twice as high as individuals living in compounds sero-negative to these antigens (Table 6).

The prevalence of sero-positive compounds for longlived antibody responses varied by antigen and region but remained generally stable throughout the transmission season. For $P f M S P 1_{19}$, prevalence of sero-positive compounds was $32.2 \%$ (95\% CI 14.9-49.5) in July 2013 and 39.8\% (95\% CI 23.6-56.0) in December 2013, while prevalence of compounds sero-positive for PfAMA1 and PfGLURP.R2 ranged between 77.0\% (95\% CI 66.9-87.1) in July 2013 and 80.7\% (95\% CI 71.5-89.9) in December 2013 (Additional file 1 - Table S1). In the Upper River Region, nearly all compounds were sero-positive to PfAMA1 and PfGLURP.R2, from 96.3\% (95\% CI 91.2100) in July 2013 to $100 \%$ in December 2014, but prevalence was slightly lower for $P f \mathrm{MSP} 1_{19}$, which was between 70.4\% (95\% CI 55.9-84.9) in July 2013 and 88.6\% (95\% CI 80.7-96.5) in December 2014. By contrast, prevalence of sero-positive compounds for shortlived antibody responses were lower in both regions, ranging from 41.4\% (95\% CI 25.3-57.5) for Etramp5.Ag1 to $63.2 \%$ (95\% CI 50.5-76.0) for EBA175 in July 2013 in the West Coast Region and from $72.2 \%$ (95\% CI $58.2-$ 86.3) for Etramp5.Ag1 in July 2013 to $97.1 \%$ (95\% CI 93.2-100) for GEXP18 in December 2014 in the Upper River Region.

Association between individual-level clinical malaria, asymptomatic infection, and compound sero-prevalence When stratifying by compound-level sero-prevalence, mean regression estimates found a reduced odds of clinical malaria if residing in a compound with seroprevalence less than $50 \%$ for all antigens and an 
Table 6 Odds of clinical malaria and asymptomatic Pf infection by compound serological status. Estimates are weighted by compound size and shown as unadjusted odds ratios (OR) and adjusted odds ratios (aOR) for age group ( $<5$ years, 5-15 years, and $>15$ years)

\begin{tabular}{|c|c|c|c|c|c|c|}
\hline \multicolumn{7}{|c|}{ Odds of clinical malaria or asymptomatic Pf infection for individuals residing in sero-positive compounds } \\
\hline & \multicolumn{3}{|c|}{ Unadjusted } & \multicolumn{3}{|c|}{ Adjusted } \\
\hline & $\overline{\mathrm{OR}}$ & $95 \% \mathrm{Cl}$ & $\boldsymbol{p}$ value & $\mathrm{aOR}$ & $95 \% \mathrm{Cl}$ & $\boldsymbol{p}$ value \\
\hline \multicolumn{7}{|l|}{ Etramp5.Ag1 } \\
\hline Clinical malaria & 0.19 & $0.03-1.06$ & 0.059 & 0.17 & $0.03-0.89$ & 0.036 \\
\hline Asymptomatic infection & 2.83 & $1.62-4.96$ & $<0.001$ & 2.87 & $1.62-5.07$ & $<0.001$ \\
\hline \multicolumn{7}{|l|}{ GEXP18 } \\
\hline Clinical malaria & 0.13 & $0.02-0.90$ & 0.039 & 0.11 & $0.02-0.73$ & 0.022 \\
\hline Asymptomatic infection & 2.65 & $1.58-4.47$ & $<0.001$ & 2.61 & $1.54-4.42$ & $<0.001$ \\
\hline \multicolumn{7}{|l|}{ HSP40.Ag1 } \\
\hline Clinical malaria & 0.14 & $0.02-0.80$ & 0.027 & 0.13 & $0.02-0.70$ & 0.018 \\
\hline Asymptomatic infection & 1.32 & $0.77-2.28$ & 0.316 & 1.38 & $0.79-2.41$ & 0.257 \\
\hline \multicolumn{7}{|l|}{ Rh2.2030 } \\
\hline Clinical malaria & 0.07 & $0.01-0.48$ & 0.006 & 0.06 & $0.01-0.35$ & 0.002 \\
\hline Asymptomatic infection & 1.69 & $0.96-2.99$ & 0.070 & 1.92 & $1.10-3.36$ & 0.022 \\
\hline \multicolumn{7}{|l|}{ EBA175 } \\
\hline Clinical malaria & 0.07 & $0.01-0.61$ & 0.016 & 0.07 & $0.01-0.57$ & 0.013 \\
\hline Asymptomatic infection & 1.00 & $0.50-2.01$ & 0.992 & 1.02 & $0.50-2.09$ & 0.954 \\
\hline \multicolumn{7}{|l|}{ PfMSP1 19} \\
\hline Clinical malaria & 0.15 & $0.03-0.87$ & 0.034 & 0.12 & $0.03-0.50$ & 0.004 \\
\hline Asymptomatic infection & 1.87 & $1.15-3.06$ & 0.012 & 1.95 & $1.19-3.20$ & 0.008 \\
\hline \multicolumn{7}{|l|}{ PfAMA1 } \\
\hline Clinical malaria & 0.06 & $0.01-0.62$ & 0.018 & 0.05 & $0.01-0.52$ & 0.011 \\
\hline Asymptomatic infection & 1.96 & $1.01-3.81$ & 0.046 & 1.99 & $1.00-3.93$ & 0.048 \\
\hline \multicolumn{7}{|l|}{ PfGLURP.R2 } \\
\hline Clinical malaria & 0.06 & $0.01-0.53$ & 0.012 & 0.05 & $0.01-0.43$ & 0.006 \\
\hline Asymptomatic infection & 1.59 & $0.85-2.97$ & 0.145 & 1.52 & $0.77-3.01$ & 0.228 \\
\hline
\end{tabular}

increased odds of clinical malaria in compounds with greater than 50\% sero-prevalence for four antigens (Etramp5.Ag1, GEXP18, HSP40.Ag1, and PfMSP1 19 ) (Fig. 5a, Additional file 2 - Tables S3, S7, S11, S19, and S23). However, these results were not statistically significant. There was strong statistical evidence for increasing odds of asymptomatic infection with increasing compound sero-prevalence for two antigens (Etramp5.Ag1 and $P f \mathrm{MSP}_{19}$ ) (Fig. 5b, Additional file 2 - Tables S4, S24) and weaker statistical evidence for increasing odds of asymptomatic infection for HSP40.Ag1 and Rh2.2030 (Additional file 2 - Tables S14, S16). Average compound size in regions with less than 15\% PCR prevalence (West Coast, North Bank, Lower River and Central River Regions) was 9.3 (95\% CI 7.9-10.7) individuals, and in regions with more than 15\% PCR prevalence (Upper River Regions South and North), average compound size was slightly larger (16.3 95\% CI $13.4-19.1$ individuals)
(Additional file 1 - Figure S1). Across all compounds, the average age range within a household was 54.2 years (95\% CI 51.2-57.1), with an average minimum age of 2.6 years $(95 \% \mathrm{CI} 2.1-3.0)$ and a maximum age of 56.7 years (95\% CI 53.8-59.8) (Additional file 1 - Figure S1).

Antigens most associated with increased odds of asymptomatic infection were Etramp5.Ag1, GEXP18, and $P$ PMSP1 $1_{19}$. For Etramp5.Ag1, aOR ranged from 2.52 (95\% CI 1.49-4.28, $p=0.001$ ) in compounds with less than $50 \%$ sero-prevalence to aOR 8.17 (95\% CI $5.23-$ $12.76, p<0.001)$ in compounds with sero-prevalence greater than $50 \%$, compared to sero-negative compounds as the baseline reference (Additional file 2 Table S4). For GEXP18, aOR ranged from 2.86 (95\% CI 1.44-5.69, $p=0.003$ ) to 8.85 (95\% CI 3.54-22.08, $p<$ 0.001) (Additional file 2 - Table S8). For $P f M S P 1_{19}$, aOR ranged from $2.13(95 \%$ CI $1.30-3.50, p=0.003)$ to aOR 8.75 (95\% CI 4.96-15.43, $p<0.001$ ) (Additional file 2 - 


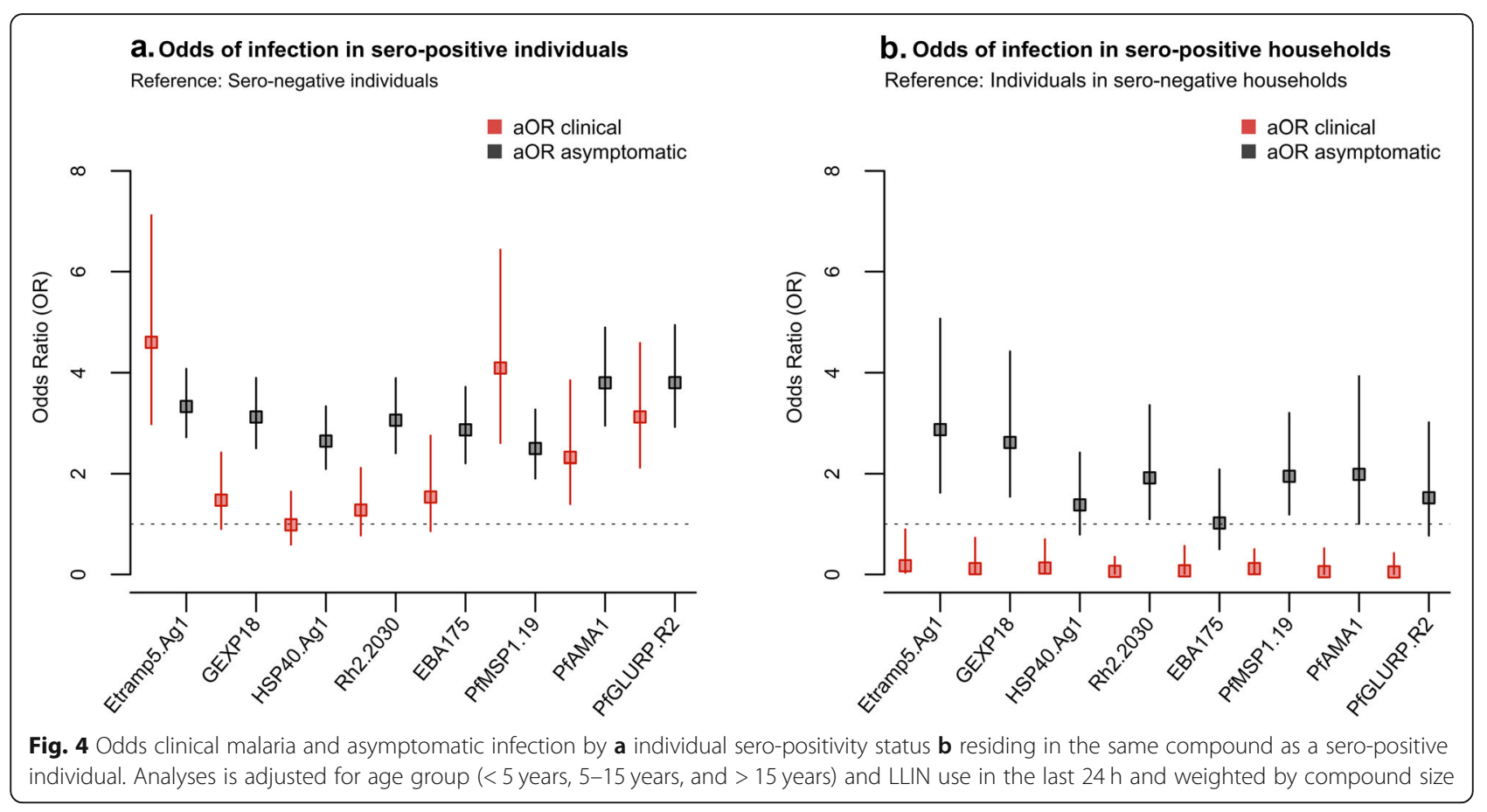

Table S24). For HSP40.Ag1, EBA175, and PfAMA1, statistically strong evidence for increased odds of asymptomatic infection was only observed in compounds with greater than $50 \%$ sero-prevalence (Additional file 2 - Tables S12, S20, S28).

The spatial distribution of infections at both the start and end of the transmission season (June-July 2013 vs. August-December 2013) suggests that clinical malaria and asymptomatic infection is localised near households with Etramp5.Ag1 sero-positive individuals (Fig. 6). There are a number of Etramp5.Ag1 seropositive households at both the start and during the wet season without concurrent clinical or asymptomatic infections present. However, this is more pronounced for PfAMA1, where sero-positivity could reflect a longer history of exposure than Etramp5.Ag1 (Additional file 3 Figure S1). While there are a limited number of clinical cases between June and July 2013, from August to
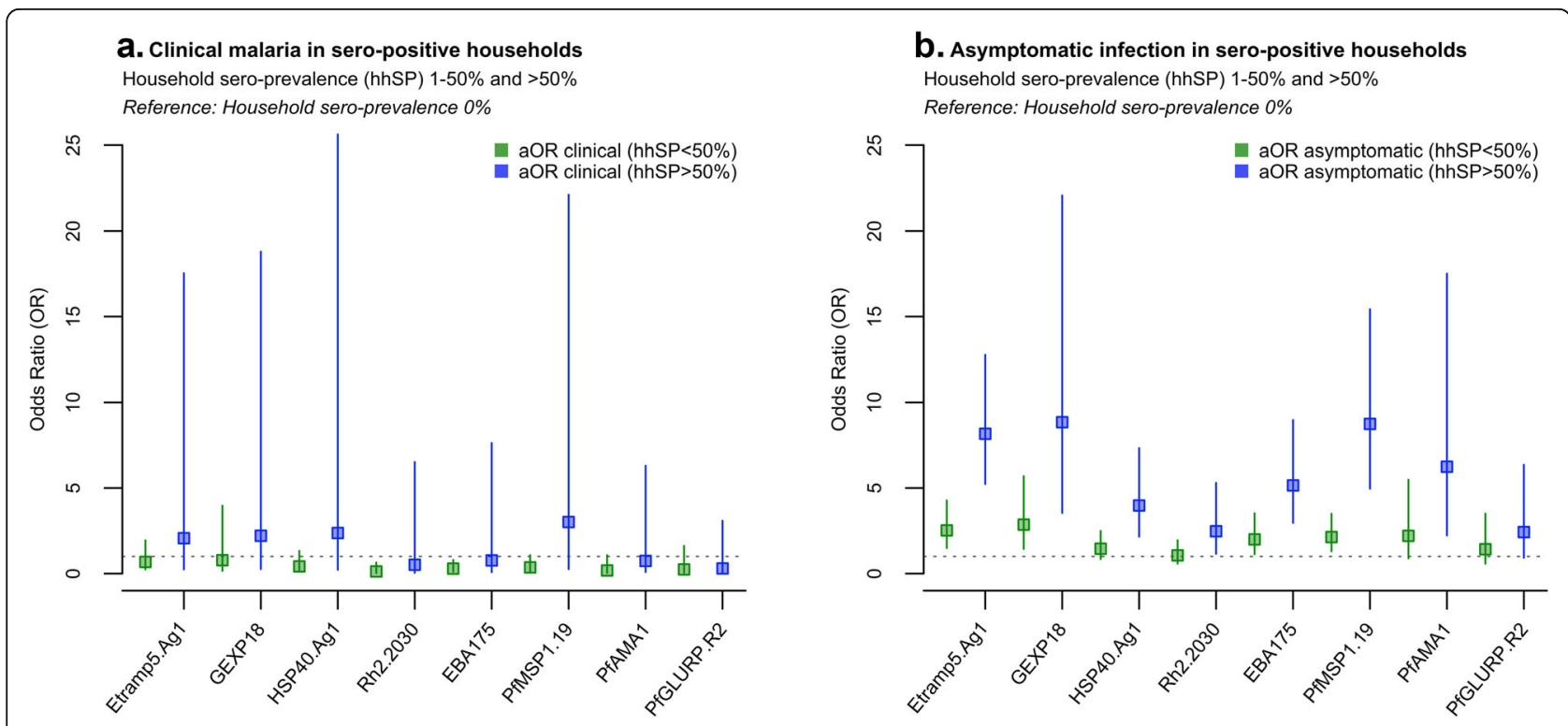

Fig. 5 Odds of clinical malaria by compound sero-prevalence (a) and odds of asymptomatic infection by compound sero-prevalence (b). Analyses is adjusted for age group ( $<5$ years, 5-15 years, and $>15$ years) and LLIN use in the last $24 \mathrm{~h}$ and weighted by compound size 

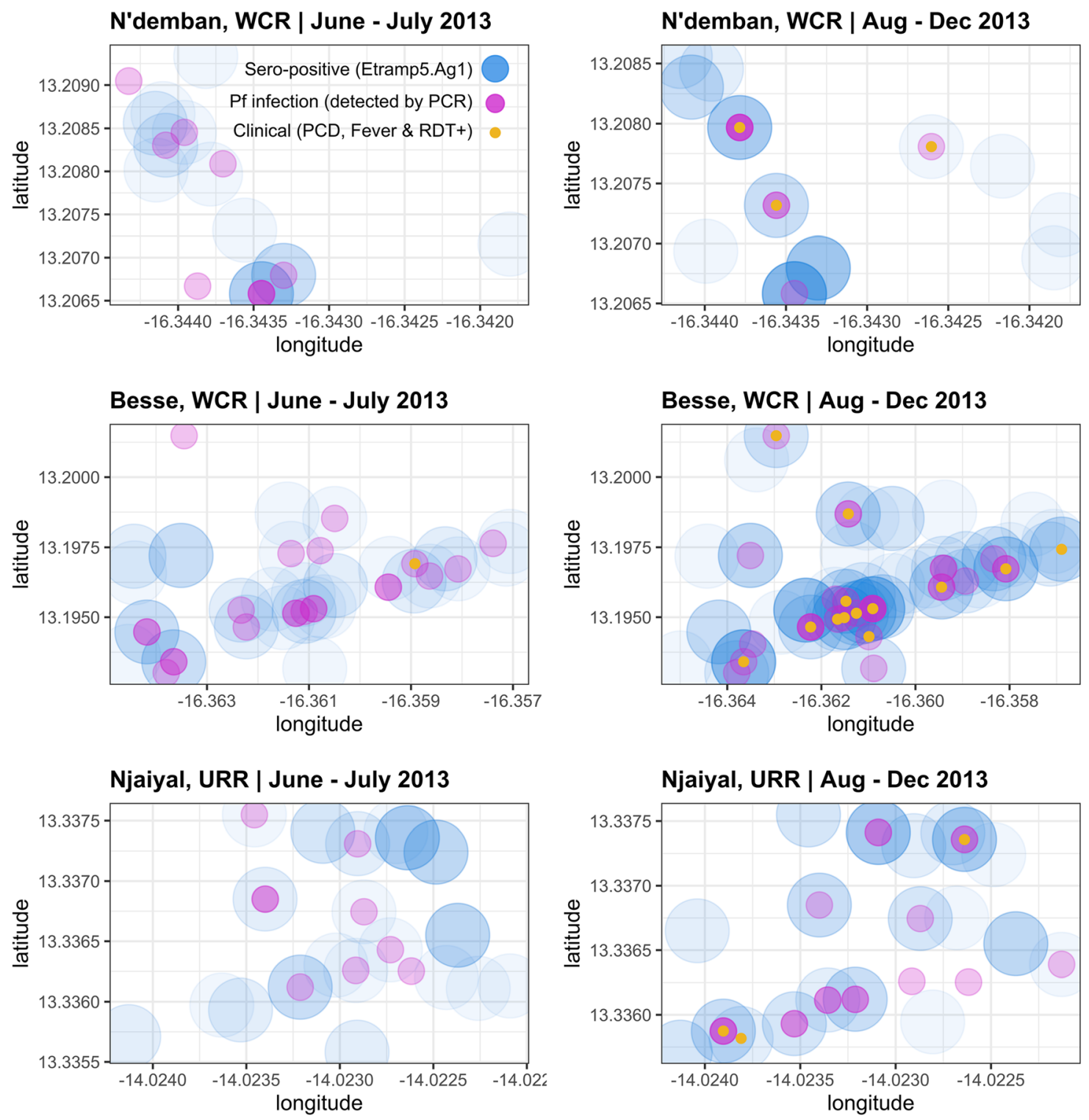

Madina Samako, URR | June - July 2013

Madina Samako, URR | Aug - Dec 2013
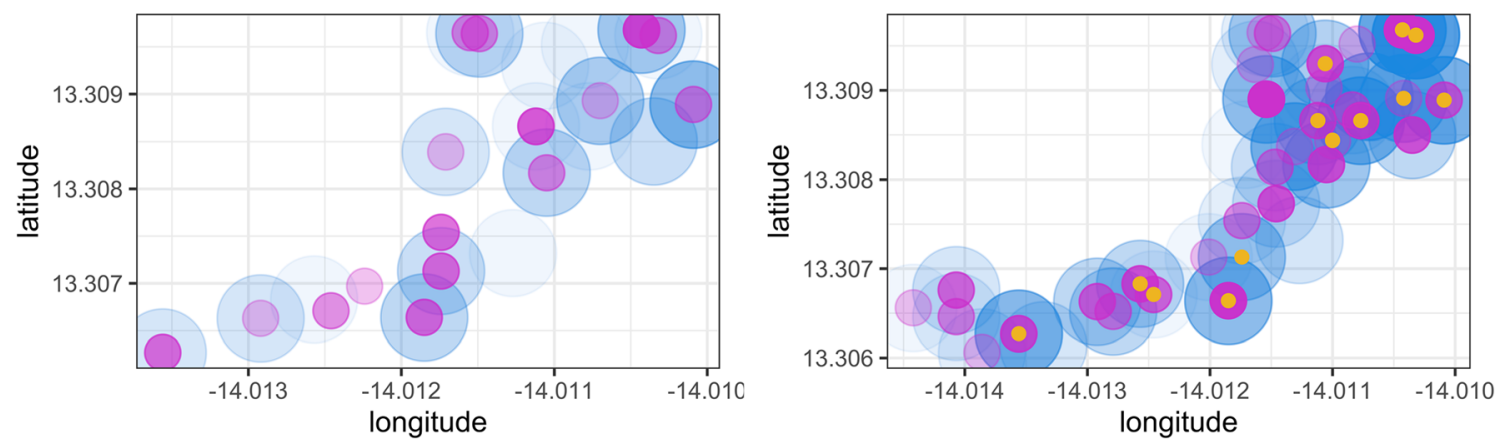

Fig. 6 Household geolocation of Etramp5.Ag1 sero-positive individuals, clinical malaria, and Pf infections across four villages. Spatial distribution of infections shown for lower transmission (N'demban) and higher transmission (Besse) villages in the West Coast Region (WCR) and lower transmission (Njaiyal) and higher transmission (Madina Samako) villages in the Upper River Region (URR). Infections at the start of the wet season (June-July 2013) shown on the left and during the wet and transmission season (August-December 2013) on the right 
December 2013, these cases occur in proximity to households with asymptomatic and Etramp5.Ag1 seropositive individuals (Fig. 6).

\section{Discussion}

We investigated the association between antibody responses and clinical and parasitological endpoints at the individual, household, and population level across The Gambia. At the individual level, clinical malaria was highly correlated with concurrent sero-positivity to Etramp5.Ag1, PfMSP1 19 , PfAMA1, and PfGLURP.R2, while asymptomatic infection was correlated with seropositivity to all antigens included in this study. The strongest associations were between asymptomatic infection and sero-positivity to Etramp5.Ag1 and PfAMA1. Village-level sero-prevalence amongst children 2-10 years against antigens Etramp5.Ag1, HSP40.Ag1, and $P f M S P 1_{19}$ showed the highest correlations with clinical incidence and $P f$ infection rates. In addition to current infection, antibody responses to several antigens, particularly Etramp5.Ag1, were associated with prior infection in the last 4 months, highlighting the potential for cross-sectional serological surveillance to identify areas of recent malaria exposure, even after parasites have been cleared and are no longer detectable by PCR. To better inform how these antigenic targets can be used to estimate time since infection, future research is needed to quantify the half-life of antibody responses and determine the sensitivity and specificity for identifying previous infection across varying epidemiological settings. This will require more detailed cohort studies with intensive follow-up for extended periods (ideally more than 1 year) and with sufficient sample sizes to capture individual heterogeneity [26].

At the household level, individuals had increased odds of asymptomatic infection when residing in a compound with greater than $50 \%$ sero-prevalence to all antigens, with the highest odds associated with sero-prevalence to Etramp5.Ag1, GEXP18, and PfMSP1 $1_{19}$. While these results cannot confirm a causal relationship between serological responses and clinical outcomes or asymptomatic infection, they indicate that infected individuals tend to be concurrently sero-positive to most of the serological markers assessed. There was strong evidence of reduced odds of clinical malaria for individuals residing in the same compound as an individual sero-positive to any of the antigens, suggesting a protective effect. In fact, previous studies suggest that several of the antigens investigated in this study-EBA175, Rh2, PfGLURP.R2, PfAMA1, and PfMSP1-have a functional role in mediating protective immunity if antibodies are acquired at a sufficiently high magnitude [27-29].

While PfMSP $1_{19}$ and PfAMA1 have been used extensively to measure medium- and long-term trends in transmission intensity, these markers may be less sensitive to changes in transmission at higher endemicities or to short-term fluctuations due to the rapid acquisition of antibodies and the long half-life of sero-positivity for some blood-stage antigens [30-33]. Individuals with clinical malaria or with long-lived antibody responses in low transmission regions of western Gambia could indicate foci of malaria transmission that have been ongoing for several transmission seasons or years. In areas where parasite density is low and often missed by RDTs and microscopy, using serological markers could support targeted interventions to clear or eliminate these residual reservoirs of human infection. Antigens in this study associated with shorter-lived antibodies-Etramp5.Ag1, GEXP18, and HSP40.Ag1-were positively correlated with clinical malaria and asymptomatic infection. Antibody responses to these antigens have been shown to decrease rapidly after infection in Ugandan children [34]. The cellular localisation of these antigenic targets makes them less likely to play a central role in mediating functional immunity, unlike antigens associated with longer-lived antibodies such as PfAMA1, PfMSP1 $1_{19}$, and EBA175. In settings where most infections are sub-patent and fluctuate above or below the detection limit of PCR, detecting the shortlived antibody responses in individuals or households could imply recent infectivity, particularly in the dry season when clinical cases are rare.

While factors such as the method for determining sero-positivity cut-off values could affect estimates of sero-prevalence or the magnitude of association between endpoints [35], the observations in this study have important implications. In particular, there is a very consistent trend of compound sero-positivity being a risk factor for asymptomatic infection in contrast to being protective against clinical malaria. The complex dynamics between clinical and parasitic immunity are not fully explained through epidemiological data alone as previous studies have observed lower PCR density in areas of higher transmission intensity [36]. Fluctuations in sero-positivity levels may be a strong indicator of a persistent human reservoir of infection, warranting community-targeted interventions if individuals remain infected but are not clinically apparent and continue to transmit. Household serological status could be used for targeting interventions where there are foci of asymptomatically infected individuals.

Immuno-epidemiological studies will be subject to variations in antigen-specific antibody dynamics, as well as the antigenicity of recombinant constructs. Differences in sequence selection and expression systems may result in recombinant proteins that differ slightly from natural epitope conformation or exposure. It is unclear the 
degree to which these subtle variations affect the strength of antibody detection between recombinant antigens. While this study focuses primarily on total IgG responses, quantification of antibody levels using a combination of isotypes or subclasses may allow for improved detection of sero-incidence. For example, some studies have found that IgG3 antibodies bind more weakly or have a reduced serum half-life relative to IgG1 $[37,38]$, suggesting that naturally acquired antibody responses can be skewed with respect to isotype and subclass. Studies on switch class variants for both malaria and other infectious pathogens have found that antibody affinity and avidity will differ between antigens of the same pathogen or even between different domains of a single antigen [39, 40]. This can be due to factors such as age and gender, antigen density, strain of the organism, and epitope specificity [38, 41, 42]. Ultimately, current evidence on the associations of antigen-specific IgG subclasses with both exposure and immunity to malaria is varied [43, 44]. Antigens will fall along a continuum of suitability as either biomarkers of acute infection to correlates of protective immunity [28], and these subtleties need to be considered when selecting targets for surveillance. The assays used in this study have allowed us to quantify antibody responses to specific antigens. Therefore, it will also be valuable to investigate the optimal combinations of antigens associated with both short- and long-lived antibodies in surveillance, which could be more routinely used to account for the breadth of antibody response in a population [45-47]. Individual level variations could also be overcome by using multiple variants or chimeric antigen constructs [48].

Changing household sero-prevalence throughout the season may influence the precision of estimates, which could be overcome with more frequent sampling of study participants, such as 3-month intervals depending on antibody decay rates. The findings in this study suggest that household sero-prevalence may be a robust proxy for past malaria exposure. It is simultaneously associated with increased risk of asymptomatic infections, but reduced risk of clinical malaria (potentially due to partial immunity). However, the biological relationship between household serological status and the risk of clinical or parasitic infection could be better investigated and confirmed through controlled observational cohort studies.

Our study findings indicate that a number of new serological markers of malaria exposure could be useful for epidemiological surveillance in highly seasonal malaria transmission areas. There is potential for several of the antigenic targets explored to be used for populationwide screening, all of which have also been optimised for use on a multiplexed bead-based platform in research settings. Further translating this to a lateral flow device may offer opportunities for widespread application if clear use-cases can be established [49]. In light of the strong association between serological status and increased asymptomatic infection, serological platforms may have direct utility as a screening tool in active or reactive case detection strategies, most of which have relied on clinical index cases presenting at health facilities and have shown variability in effectiveness [50]. As malaria transmission declines, surveillance using a diverse panel of antigenic targets can complement existing and emerging diagnostic tools for monitoring changes in transmission. This can include methods such as agestratified sero-prevalence to estimate sero-conversion rates or measuring age-specific antibody intensity, where estimates of the magnitude of antibody response can often detect more subtle serological changes in the population [51]. Specific monitoring for the presence of individuals or households with higher than age-expected antibody levels, as has been explored in other elimination settings such as Indonesia [52] and South Africa [10], can also be used to identify areas with clustering of high antibody responses as potential reservoirs of infections and guide the spatial targeting of interventions. Serology could also play a role in documenting the absence of malaria transmission, inform baseline risk stratification of study arms in randomised trials, or be used as secondary endpoints in efficacy trials [49]. However, further field testing of these strategies in future studies will be needed, as well as standardised methods for characterising serological responses at the village or cluster level, and determining optimal sampling timeframes or sentinel populations for use in routine surveillance.

\section{Conclusions}

As more countries move towards malaria elimination, including several in sub-Saharan Africa, sensitive surveillance tools will be needed to further understand the dynamics between the parasite, host, and vector at very low levels of transmission. Integrating serological markers of recent exposure into existing field diagnostics and case reporting will become increasingly important in estimating the human reservoir of malaria infection, understanding patterns of transmission, and designing targeted elimination strategies.

\section{Supplementary information}

Supplementary information accompanies this paper at https://doi.org/10. 1186/s12916-020-01724-5.

Additional file 1. Sero-prevalence amongst individuals aged 2-10 year, prevalence of sero-positive compounds, and population size and age distribution by compound.

Additional file 2. Odds of clinical malaria and asymptomatic infection for sero-positive individuals and individuals residing in sero-positive compounds. Unadjusted and adjusted odds ratios for eight malaria antigenic 
targets - Etramp5.Ag1, GEXP18, HSP40.Ag1, Rh2.2030, EBA175, PfMSP1 19 PFAMA1, and PFGLURP.R2

Additional file 3. Map of household geolocation of PFAMA1 seropositive, clinical malaria and Pf infections across four villages during dry and wet transmission seasons. Spatial distribution of infections shown for lower transmission (N'demban) and higher transmission (Besse) villages in the West Coast Region (WCR) and lower transmission (Njaiyal) and higher transmission (Madina Samako) villages in the Upper River Region (URR). Infections at the start of the wet season (June - July 2013) shown on the left and during the wet and transmission season (August - December 2013) on the right.

Additional file 4. Gambia serology endpoints study data.

\section{Abbreviations}

aOR: Adjusted odds ratio; Cl: Confidence interval; DBS: Dried blood spot; EBA175, RIII-V: Erythrocyte-binding antigen 175 Region III-V ; Etramp5.Ag1: Early transcribed membrane protein 5; GEE: Generalised estimating equation; GEXP18: Gametocyte export protein 18; HSP40.Ag1: Heat shock protein 40; IgG: Immunoglobulin; LLIN: Long-lasting insecticide-treated net; MDA: Mass drug administration; MFI: Median fluorescence intensity; PCD: Passive case detection; PCR: Polymerase chain reaction; Pf, P. falciparum: Plasmodium falciparum; PfAMA1: P. falciparum apical membrane antigen 1; PfMSP1 ${ }_{19}$ : P. falciparum merozoite surface antigen 1 19-kDa carboxy-terminal region; RDT: Rapid diagnostic test; Rh2.2030: Reticulocyte binding protein homologue 2; URR: Upper River Region, The Gambia; WCR: West Coast Region, The Gambia

\section{Acknowledgements}

Thanks to Linda Reiling and Christine Langer (Burnet Institute) for help with recombinant protein expression.

\section{Authors' contributions}

LW designed and coordinated the study, supervised and performed serological lab work, analysed the data, and wrote the manuscript. JM and MA supervised field data collection and laboratory work. SC and MB conducted the serological assays. KKAT, SKS, and JGB produced the antigens, advised on the interpretation of findings, and reviewed the manuscript. KKAT and $T H$ developed the serological assay. JM, MA, UD, IK, and CD advised on study design, interpretation of findings, and reviewed the manuscript. All authors read and approved the final manuscript.

\section{Funding}

This study was funded by the UK Medical Research Council (UK MRC) through the LSHTM Doctoral Training Programme studentship received by LW (MR/ J003999/1). JGB was supported by the National Health and Medical Research Council of Australia (Investigator Grant 1173046, Program Grant 1092789). Burnet Institute is supported by the NHMRC Independent Research Institute Infrastructure Support Scheme and a Victorian State Government Operational Infrastructure grant. The funders had no role in the design of the study, collection, analysis, interpretation of data, or writing of the manuscript.

\section{Availability of data and materials}

The datasets used and/or analysed during the current study are provided as an Additional file 4, but personally identifying information on village and compound have been removed to maintain confidentiality. Access to this data can be made available from the corresponding author on reasonable request.

\section{Ethics approval and consent to participate}

This study was approved by The Gambia Government/MRC Joint Ethics Committee (SCC1318). Verbal consent was first obtained at village sensitisation meetings, followed by individual written informed consent for all participants. Parents/guardians provided written consent for children less than 17 years, and assent was obtained from children between 12 and 17 years.

\section{Consent for publication}

Not applicable

\section{Competing interests}

All authors declare no competing interests.

\section{Author details}

${ }^{1}$ Faculty of Infectious Tropical Diseases, Department of Infection Biology, London School of Hygiene and Tropical Medicine (LSHTM), London WC1E 7HT, UK. ${ }^{2}$ Medical Research Council Unit The Gambia at London School of Hygiene and Tropical Medicine, Fajara, The Gambia. ${ }^{3}$ Bernhard Nocht Institute for Tropical Medicine (BNITM), Arusha, Tanzania. ${ }^{4}$ St. George's University of London (SGUL), London, UK. ${ }^{5}$ Department for Congenital Disorders, Statens Serum Institut, Copenhagen, Denmark. ${ }^{6}$ Centre for Medical Parasitology at Department of Immunology and Microbiology, University of Copenhagen, Copenhagen, Denmark. ${ }^{7}$ Burnet Institute, Melbourne, Australia. ${ }^{8}$ Central Clinical School, Monash University, Melbourne, Victoria, Australia. ${ }^{9}$ Department of Medicine, University of Melbourne, Melbourne, Victoria, Australia. ${ }^{10}$ Faculty of Epidemiology and Population Health, Department of Infectious Disease Epidemiology, London School of Hygiene and Tropical Medicine (LSHTM), London WC1E 7HT, UK. " School of Pathology, Wits Institute for Malaria Research, Faculty of Health Science, University of Witwatersrand, Johannesburg, South Africa.

Received: 15 April 2020 Accepted: 30 July 2020

Published online: 25 September 2020

\section{References}

1. Okell LC, Bousema T, Griffin JT, Ouédraogo AL, Ghani AC, Drakeley CJ. Factors determining the occurrence of submicroscopic malaria infections and their relevance for control. Nat Commun. 2012;3:1237 Available from: http://www.ncbi.nlm.nih.gov/pubmed/23212366. [cited 2016 Apr 5].

2. Bousema T, Okell L, Felger I, Drakeley C. Asymptomatic malaria infections: detectability, transmissibility and public health relevance. Nat Rev Microbiol. 2014;12(12):833-40 Available from: http://www.ncbi.nlm.nih.gov/ pubmed/25329408. [cited 2016 Apr 5].

3. Wu L, van den Hoogen LL, Slater H, Walker PGT, Ghani AC, Drakeley CJ, et al. Comparison of diagnostics for the detection of asymptomatic Plasmodium falciparum infections to inform control and elimination strategies. Nature. 2015;528(7580):S86-93 Available from: http://www.ncbi. nlm.nih.gov/pubmed/26633770. [cited 2016 Apr 5].

4. Andrews L, Andersen RF, Webster D, Dunachie S, Walther RM, Bejon P, et al. Quantitative real-time polymerase chain reaction for malaria diagnosis and its use in malaria vaccine clinical trials. Am J Trop Med Hyg. 2005;73(1):1918 Available from: http://www.ncbi.nlm.nih.gov/pubmed/16014857. [cited 2017 Nov 21].

5. Rockett RJ, Tozer SJ, Peatey C, Bialasiewicz S, Whiley DM, Nissen MD, et al. A real-time, quantitative PCR method using hydrolysis probes for the monitoring of Plasmodium falciparum load in experimentally infected human volunteers. Malar J. 2011;10:48.

6. Okebe J, Affara M, Correa S, Muhammad AK, Nwakanma D, Drakeley C, et al. School-based countrywide seroprevalence survey reveals spatial heterogeneity in malaria transmission in the Gambia. Fernandez-Reyes D, editor. PLoS One 2014;9(10):e1 10926. Available from: http://www.ncbi.nlm. nih.gov/pubmed/25338083. [cited 2018 May 12].

7. van den Hoogen LL, Griffin JT, Cook J, Sepúlveda N, Corran P, Conway DJ, et al. Serology describes a profile of declining malaria transmission in Farafenni, The Gambia. Malar J. 2015;14(1):416 Available from: http://www. malariajournal.com/content/14/1/416. [cited 2018 Jun 13].

8. Drakeley CJ, Corran PH, Coleman PG, Tongren JE, McDonald SLR, Carneiro I, et al. Estimating medium- and long-term trends in malaria transmission by using serological markers of malaria exposure. Proc Natl Acad Sci U S A. 2005;102(14):5108-13 Available from: http://www.ncbi.nlm.nih.gov/ pubmed/15792998. [cited 2017 Oct 30].

9. Cook J, Kleinschmidt I, Schwabe C, Nseng G, Bousema T, Corran PH, et al. Serological markers suggest heterogeneity of effectiveness of malaria control interventions on Bioko Island, equatorial Guinea. PLoS One. 2011; 6(9):e25137 Available from: http://journals.plos.org/plosone/article?id=10.13 71/journal.pone.0025137. [cited 2015 Jun 16].

10. Biggs J, Raman J, Cook J, Hlongwana K, Drakeley C, Morris N, et al. Serology reveals heterogeneity of Plasmodium falciparum transmission in northeastern South Africa: implications for malaria elimination. Malar J. 2017; 16(1):48 Available from: http://malariajournal.biomedcentral.com/articles/1 0.1186/s12936-017-1701-7. [cited 2018 Aug 15]. 
11. Helb DA, Tetteh KKA, Felgner PL, Skinner J, Hubbard A, Arinaitwe E, et al Novel serologic biomarkers provide accurate estimates of recent Plasmodium falciparum exposure for individuals and communities. Proc Natl Acad Sci U S A. 2015;112(32):E4438-47 Available from: http://www.ncbi.nlm. nih.gov/pubmed/26216993. [cited 2017 Oct 30].

12. Kerkhof K, Sluydts V, Willen L, Kim S, Canier L, Heng S, et al. Serological markers to measure recent changes in malaria at population level in Cambodia. Malar J. 2016;15(1):529 Available from: http://malariajournal. biomedcentral.com/articles/10.1186/s12936-016-1576-z. [cited 2017 Nov 1].

13. Mwesigwa J, Achan J, Di Tanna GL, Affara M, Jawara M, Worwui A, et al. Residual malaria transmission dynamics varies across The Gambia despite high coverage of control interventions. Carvalho LH, editor. PLoS One. 2017; 12(11):e0187059 Available from: http://dx.plos.org/10.1371/journal.pone.01 87059. [cited 2018 Feb 5].

14. Burghaus PA, Holder AA. Expression of the 19-kilodalton carboxy-terminal fragment of the Plasmodium falciparum merozoite surface protein-1 in Escherichia coli as a correctly folded protein. Mol Biochem Parasitol. 1994; 64(1):165-9 Available from: https://www.sciencedirect.com/science/article/ pii/0166685194901449?via\%3Dihub. [cited 2018 Apr 26].

15. Collins CR, Withers-Martinez C, Bentley GA, Batchelor AH, Thomas AW, Blackman MJ. Fine mapping of an epitope recognized by an invasioninhibitory monoclonal antibody on the malaria vaccine candidate apical membrane antigen 1. J Biol Chem. 2007;282(10):7431-41 Available from: http://www.ncbi.nlm.nih.gov/pubmed/17192270. [cited 2018 Apr 26].

16. Theisen M, Vuust J, Gottschau A, Jepsen S, Høgh B. Antigenicity and immunogenicity of recombinant glutamate-rich protein of Plasmodium falciparum expressed in Escherichia coli. 1995;2(1):30-4. Available from: http://cvi.asm.org/content/2/1/30.full.pdf. [cited 2018 Apr 26].

17. Richards JS, Stanisic DI, Fowkes FJI, Tavul L, Dabod E, Thompson JK, et al. Association between naturally acquired antibodies to erythrocyte-binding antigens of Plasmodium falciparum and protection from malaria and highdensity parasitemia. Clin Infect Dis. 2010;51(8):e50-60 Available from: https:// academic.oup.com/cid/article-lookup/doi/10.1086/656413. [cited 2018 Apr 26].

18. Triglia T, Thompson J, Caruana SR, Delorenzi M, Speed T, Cowman AF. Identification of proteins from Plasmodium falciparum that are homologous to reticulocyte binding proteins in Plasmodium vivax. Infect Immun. 2001; 69(2):1084-92 Available from: http://www.ncbi.nlm.nih.gov/pubmed/1116 0005. [cited 2018 Apr 26].

19. Spielmann T, Fergusen DJP, Beck H-P. etramps, a new Plasmodium falciparum gene family coding for developmentally regulated and highly charged membrane proteins located at the parasite-host cell interface. Mol Biol Cell. 2003;14(4):1529-44 Available from: http://www.ncbi.nlm.nih.gov/ pubmed/12686607. [cited 2018 Apr 26].

20. Herman LS, Fornace K, Phelan J, Grigg MJ, Anstey NM, William T, et al. Identification and validation of a novel panel of Plasmodium knowlesi biomarkers of serological exposure. Barry AE, editor. PLoS Negl Trop Dis. 2018;12(6):e0006457 Available from: https://dx.plos.org/10.1371/journal.pntd. 0006457. [cited 2020 Apr 1].

21. Tetteh KKA, Osier FHA, Salanti A, Kamuyu G, Drought L, Failly M, et al. Analysis of antibodies to newly described plasmodium falciparum merozoite antigens supports MSPDBL2 as a predicted target of naturally acquired immunity. Infect Immun. 2013;81(10):3835-42.

22. Polley SD, Tetteh KKA, Cavanagh DR, Pearce RJ, Lloyd JM, Bojang KA, et al. Repeat sequences in block 2 of Plasmodium falciparum merozoite surface protein 1 are targets of antibodies associated with protection from malaria. Infect Immun. 2003;71(4):1833-42.

23. Wu L, Hall T, Ssewanyana I, Oulton T, Patterson C, Vasileva H, et al. Optimisation and standardisation of a multiplex immunoassay of diverse Plasmodium falciparum antigens to assess changes in malaria transmission using sero-epidemiology. Wellcome Open Res. 2019;4:26 Available from: https://wellcomeopenresearch.org/articles/4-26/v1. [cited 2019 Mar 5].

24. Snounou G. Genotyping of Plasmodium spp. Nested PCR Methods Mol Med. 2002;72:103-16.

25. Stewart L, Gosling R, Griffin J, Gesase S, Campo J, Hashim R, et al. Rapid assessment of malaria transmission using age-specific sero-conversion rates. PLoS One. 2009;4(6):e6083 Available from: http://journals.plos.org/plosone/ article?id=10.1371/journal.pone.0006083. [cited 2015 Jun 19].

26. Greenhouse B, Smith DL, Rodríguez-Barraquer I, Mueller I, Drakeley CJ. Taking sharper pictures of Malaria with CAMERAs: Combined antibodies to measure exposure recency assays. Am J Trop Med Hygiene. 2018;99:1120-7 Available from: /pmc/articles/PMC6221205/?report=abstract. [cited 2020 Jul 20].
27. Murungi LM, Kamuyu G, Lowe B, Bejon P, Theisen M, Kinyanjui SM, et al. A threshold concentration of anti-merozoite antibodies is required for protection from clinical episodes of malaria. Vaccine. 2013;31(37):3936-42 Available from: /pmc/articles/PMC3763364/?report=abstract. [cited 2020 Jun 24].

28. Stanisic DI, Fowkes FJl, Koinari M, Javati S, Lin E, Kiniboro B, et al. Acquisition of antibodies against Plasmodium falciparum merozoites and malaria immunity in young children and the influence of age, force of infection, and magnitude of response. Infect Immun. 2015;83(2):646-60 Available from: http://www.ncbi.nlm.nih.gov/pubmed/25422270. [cited 2018 Apr 30].

29. Reiling L, Boyle MJ, White MT, Wilson DW, Feng G, Weaver R, et al. Targets of complement-fixing antibodies in protective immunity against malaria in children. Nat Commun. 2019;10(1):1-13 Available from: https://www.nature. com/articles/s41467-019-08528-z. [cited 2020 Jun 24].

30. Drakeley CJ, Corran PH, Coleman PG, Tongren JE, McDonald SLR, Carneiro I, et al. Estimating medium- and long-term trends in malaria transmission by using serological markers of malaria exposure. Proc Natl Acad Sci U S A. 2005;102(14): 5108-13 Available from: http://www.pubmedcentral.nih.gov/articlerender. fcgi?artid=555970\&tool=pmcentrez\&rendertype=abstract. [cited 2015 Jun 5].

31. Bruce-Chwatt $L$, Draper CC, Konfortion P. Seroepidemiological evidence of eradication of malaria from Mauritius. Lancet (London). 1973;2(7828):547-51 Available from: http://www.ncbi.nlm.nih.gov/pubmed/4125305. [cited 2015 Jul 13].

32. Wong J, Hamel MJ, Drakeley CJ, Kariuki S, Shi YP, Lal AA, et al. Serological markers for monitoring historical changes in malaria transmission intensity in a highly endemic region of Western Kenya, 1994-2009. Malar J. 2014; 13(1):451 Available from: http://www.malariajournal.com/content/13/1/451. [cited 2015 May 29].

33. Yman V, White MT, Rono J, Arcà B, Osier FH, Troye-Blomberg M, et al. Antibody acquisition models: a new tool for serological surveillance of malaria transmission intensity. Sci Rep. 2016;6(1):19472 Available from: http://www.nature.com/articles/srep19472. [cited 2017 Nov 1].

34. Helb DA, Tetteh KKA, Felgner PL, Skinner J, Hubbard A, Arinaitwe E, et al. Novel serologic biomarkers provide accurate estimates of recent Plasmodium falciparum exposure for individuals and communities. Proc Natl Acad Sci U S A. 2015;112(32):E4438-47 Available from: http://www.ncbi.nlm. nih.gov/pubmed/26216993. [cited 2015 Jul 31].

35. Irion A, Beck HP, Smith T. Assessment of positivity in immuno-assays with variability in background measurements: a new approach applied to the antibody response to Plasmodium falciparum MSP2. J Immunol Methods. 2002;259(1-2):111-8 Available from: http://www.ncbi.nlm.nih.gov/ pubmed/11730846. [cited 2018 may 31].

36. Mosha JF, Sturrock HJW, Greenhouse B, Greenwood B, Sutherland CJ, Gadalla N, et al. Epidemiology of subpatent Plasmodium falciparum infection: implications for detection of hotspots with imperfect diagnostics. Malar J. 2013;12:221 Available from: http://www.ncbi.nlm.nih.gov/ pubmed/23815811. [cited 2016 Apr 5].

37. Vidarsson G, Dekkers G, Rispens T. IgG subclasses and allotypes: from structure to effector functions. Front Immunol. 2014;5 Available from: https://www.ncbi. nlm.nih.gov/pmc/articles/PMC4202688/. [cited 2018 Jun 10].

38. Irani V, Guy AJ, Andrew D, Beeson JG, Ramsland PA, Richards JS. Molecular properties of human $\operatorname{lgG}$ subclasses and their implications for designing therapeutic monoclonal antibodies against infectious diseases. Mol Immunol. 2015;67:171-82 Available from: https://pubmed.ncbi.nlm.nih. gov/25900877/. [cited 2020 Jun 27].

39. Richards JS, Stanisic DI, Fowkes FJI, Tavul L, Dabod E, Thompson JK, et al. Association between naturally acquired antibodies to erythrocyte-binding antigens of Plasmodium falciparum and protection from malaria and highdensity parasitemia. Clin Infect Dis. 2010;51(8):e50-60 Available from: https://pubmed.ncbi.nlm.nih.gov/20843207/. [cited 2020 Jun 27].

40. Stanisie DI, Richards JS, McCallum FJ, Michon P, King CL, Schoepflin S, et al. Immunoglobulin G subclass-specific responses against Plasmodium falciparum merozoite antigens are associated with control of parasitemia and protection from symptomatic illness. Infect Immun. 2009;77:1165-74 Available from: https://pubmed.ncbi.nlm.nih.gov/19139189/. [cited 2020 Jun 27].

41. Perez-Perez GI, Maw AM, Feingold-Link L, Gunn J, Bowers AL, Minano C, et al. Longitudinal analysis of serological responses of adults to Helicobacter pylori antigens. J Infect Dis. 2010;202(6):916-23 Available from: https:// pubmed.ncbi.nlm.nih.gov/20698790/. [cited 2020 Jun 27].

42. Simon B, Kundi M, Puchhammer-Stöckl E. Association of HCMV specific lgG subclass antibody levels with gender and age. Exp Gerontol. 2013;48(5):472-5 Available from: https://pubmed.ncbi.nlm.nih.gov/23422355/. [cited 2020 Jun 27]. 
43. Dobaño C, Quelhas D, Quintó L, Puyol L, Serra-Casas E, Mayor A, et al. Agedependent lgG subclass responses to Plasmodium falciparum EBA-175 are differentially associated with incidence of malaria in Mozambican children. Clin Vaccine Immunol. 2012;19(2):157-66 Available from: http://www.ncbi. nIm.nih.gov/pubmed/22169088. [cited 2018 may 28].

44. Tongren JE, Drakeley CJ, McDonald SLR, Reyburn HG, Manjurano A, Nkya WMM, et al. Target antigen, age, and duration of antigen exposure independently regulate immunoglobulin $\mathrm{G}$ subclass switching in malaria. Infect Immun. 2006;74(1):257-64 Available from: http://www.ncbi.nlm.nih. gov/pubmed/16368979. cited 2018 Apr 30].

45. Takala SL, Plowe CV. Genetic diversity and malaria vaccine design, testing and efficacy: preventing and overcoming 'vaccine resistant malaria.'. Parasite Immunol. 2009;31(9):560-73 Available from: http://www.ncbi.nlm.nih.gov/ pubmed/19691559. [cited 2018 Jun 7].

46. Scherf A, Lopez-Rubio JJ, Riviere L. Antigenic variation in Plasmodium falciparum. Annu Rev Microbiol. 2008;62(1):445-70 Available from: http:// www.ncbi.nlm.nih.gov/pubmed/18785843. [cited 2018 Jun 7].

47. Neafsey DE, Juraska M, Bedford T, Benkeser D, Valim C, Griggs A, et al. Genetic diversity and protective efficacy of the RTS,S/AS01 malaria vaccine. N Engl J Med. 2015;373(21):2025-37 Available from: http://www.nejm.org/ doi/10.1056/NEJMoa1505819. [cited 2018 Apr 30].

48. Krishnarjuna B, Andrew D, MacRaild CA, Morales RAV, Beeson JG, Anders RF, et al. Strain-transcending immune response generated by chimeras of the malaria vaccine candidate merozoite surface protein 2. Sci Rep. 2016;6(1): 20613 Available from: http://www.nature.com/articles/srep20613. [cited 2018 Jun 18].

49. Greenhouse B, Daily J, Guinovart C, Goncalves B, Beeson J, Bell D, et al. Priority use cases for antibody-detecting assays of recent malaria exposure as tools to achieve and sustain malaria elimination. Gates Open Res. 2019;3: 131 Available from: https://gatesopenresearch.org/articles/3-131/v1. [cited 2019 Mar 5].

50. Hsiang MS, Ntshalintshali N, Kang Dufour M-S, Dlamini N, Nhlabathi N, Vilakati S, et al. Active case finding for malaria: a 3-year national evaluation of optimal approaches to detect infections and hotspots through reactive case detection in the low-transmission setting of Eswatini. Clin Infect Dis. 2019; Available from: http://www.ncbi.nlm.nih.gov/pubmed/31095677. [cited 2020 Feb 19].

51. Yman V, White MT, Rono J, Arcà B, Osier FH, Troye-Blomberg M, et al. Antibody acquisition models: a new tool for serological surveillance of malaria transmission intensity. Sci Rep. 2016;5:6.

52. Surendra H, Supargiyono ARA, Kusumasari RA, Rahayujati TB, Damayanti SY, et al. Using health facility-based serological surveillance to predict receptive areas at risk of malaria outbreaks in elimination areas. BMC Med. 2020;18(1): 9 Available from: https://bmcmedicine.biomedcentral.com/articles/10.1186/ s12916-019-1482-7. [cited 2020 Jul 20].

\section{Publisher's Note}

Springer Nature remains neutral with regard to jurisdictional claims in published maps and institutional affiliations.

Ready to submit your research? Choose BMC and benefit from:

- fast, convenient online submission

- thorough peer review by experienced researchers in your field

- rapid publication on acceptance

- support for research data, including large and complex data types

- gold Open Access which fosters wider collaboration and increased citations

- maximum visibility for your research: over $100 \mathrm{M}$ website views per year

At $\mathrm{BMC}$, research is always in progress.

Learn more biomedcentral.com/submissions 


\section{University Library}

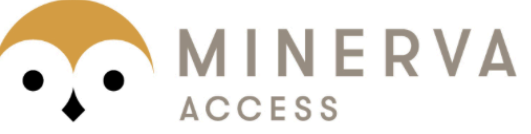

A gateway to Melbourne's research publications

Minerva Access is the Institutional Repository of The University of Melbourne

Author/s:

Wu, L;Mwesigwa, J;Affara, M;Bah, M;Correa, S;Hall, T;Singh, SK;Beeson, JG;Tetteh, KKA;Kleinschmidt, I;D'Alessandro, U;Drakeley, C

Title:

Antibody responses to a suite of novel serological markers for malaria surveillance demonstrate strong correlation with clinical and parasitological infection across seasons and transmission settings in The Gambia

Date:

2020-09-25

Citation:

Wu, L., Mwesigwa, J., Affara, M., Bah, M., Correa, S., Hall, T., Singh, S. K., Beeson, J. G., Tetteh, K. K. A., Kleinschmidt, I., D'Alessandro, U. \& Drakeley, C. (2020). Antibody responses to a suite of novel serological markers for malaria surveillance demonstrate strong correlation with clinical and parasitological infection across seasons and transmission settings in The Gambia. BMC MEDICINE, 18 (1), https://doi.org/10.1186/ s12916-020-01724-5.

Persistent Link:

http://hdl.handle.net/11343/251623

License:

CC BY 